\title{
Measured and modeled humidification factors of fresh smoke particles from biomass burning: role of inorganic constituents
}

\author{
J. L. Hand ${ }^{1}$, D. E. Day ${ }^{1}$, G. M. McMeeking ${ }^{2, *}$, E. J. T. Levin ${ }^{2}$, C. M. Carrico² ${ }^{2}$ S. M. Kreidenweis ${ }^{2}$, W. C. Malm ${ }^{3}$, \\ A. Laskin ${ }^{4}$, and Y. Desyaterik ${ }^{4,2}$ \\ ${ }^{1}$ Cooperative Institute for Research in the Atmosphere, Colorado State University, Fort Collins, Colorado, USA \\ ${ }^{2}$ Department of Atmospheric Science, Colorado State University, Fort Collins, Colorado, USA \\ ${ }^{3}$ National Park Service, Cooperative Institute for Research in the Atmosphere, Colorado State University, Fort Collins, \\ Colorado, USA \\ ${ }^{4}$ William R. Wiley Environmental Molecular Sciences Laboratory, Pacific Northwest National Laboratory, Richland \\ Washington, USA \\ *now at: Center for Atmospheric Science, University of Manchester, Manchester, UK
}

Received: 27 January 2010 - Published in Atmos. Chem. Phys. Discuss.: 12 February 2010

Revised: 15 June 2010 - Accepted: 21 June 2010 - Published: 9 July 2010

\begin{abstract}
During the 2006 FLAME study (Fire Laboratory at Missoula Experiment), laboratory burns of biomass fuels were performed to investigate the physico-chemical, optical, and hygroscopic properties of fresh biomass smoke. As part of the experiment, two nephelometers simultaneously measured dry and humidified light scattering coefficients $\left(b_{\mathrm{sp}(\mathrm{dry})}\right.$ and $b_{\mathrm{sp}(\mathrm{RH})}$, respectively) in order to explore the role of relative humidity $(\mathrm{RH})$ on the optical properties of biomass smoke aerosols. Results from burns of several biomass fuels from the west and southeast United States showed large variability in the humidification factor $\left(f(\mathrm{RH})=b_{\mathrm{sp}(\mathrm{RH})} / b_{\mathrm{sp}(\mathrm{dry})}\right)$. Values of $f(\mathrm{RH})$ at $\mathrm{RH}=80-85 \%$ ranged from 0.99 to 1.81 depending on fuel type. We incorporated measured chemical composition and size distribution data to model the smoke hygroscopic growth to investigate the role of inorganic compounds on water uptake for these aerosols. By assuming only inorganic constituents were hygroscopic, we were able to model the water uptake within experimental uncertainty, suggesting that inorganic species were responsible for most of the hygroscopic growth. In addition, humidification factors at $80-85 \%$ RH increased for smoke with increasing inorganic salt to carbon ratios. Particle morphology as observed from
\end{abstract}

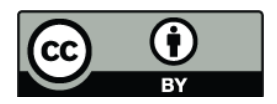

Correspondence to: J. L. Hand (hand@cira.colostate.edu) scanning electron microscopy revealed that samples of hygroscopic particles contained soot chains either internally or externally mixed with inorganic potassium salts, while samples of weak to non-hygroscopic particles were dominated by soot and organic constituents. This study provides further understanding of the compounds responsible for water uptake by young biomass smoke, and is important for accurately assessing the role of smoke in climate change studies and visibility regulatory efforts.

\section{Introduction}

The significant contribution of biomass burning emissions to the global and regional aerosol burden has been documented by several studies (e.g. Park et al., 2003, 2007; Spracklen et al., 2007). Quantifying the role of biomass burning aerosols in climate forcing and visibility degradation requires characterizing their optical, physical, chemical and hygroscopic properties. Many studies have been performed in the ambient atmosphere to measure radiative properties of smoke particles from wild fire and prescribed burning (see the review by Reid et al., 2005a, b). However, interpreting these results is complicated due to the variety of conditions under which the smoke was generated in the ambient atmosphere. Typically, ambient smoke is generated by the combustions of

Published by Copernicus Publications on behalf of the European Geosciences Union. 
a combination of biomass fuels of varying moisture, under a variety of flame conditions and is also affected by atmospheric aging. Previous studies have provided a wealth of data for ambient biomass smoke properties and are necessary to understand smoke behavior in the atmosphere. However, measurements performed in combustion facilities also provide opportunities to further investigate specific biomass smoke properties under known conditions, such as for a given fuel type and flame condition.

The Fire Laboratory at Missoula Experiment (FLAME) was designed to investigate many important questions regarding smoke properties from biomass burning. These experiments were conducted at the US Forest Service's Fire Science Laboratory in Missoula MT in 2006 and 2007. Results from several subsets of these experiments include particle and gas emissions (McMeeking et al., 2009; Chakrabarty et al., 2006; Chen et al., 2006, 2007; Engling et al., 2006; Smith et al., 2009; Laskin et al., 2009), smoke marker properties (Sullivan et al., 2008), particle physical and optical properties (Hopkins et al., 2007; Lewis et al., 2009; Levin et al., 2010), aerosol hygroscopicity, cloud condensation and ice nucleation ability (Day et al., 2006; Carrico et al., 2008, 2010; Petters et al., 2009; Demott et al., 2009). Burns were performed on fuels that represented biomass found in locations often involved in wild and prescribed fires, such as in the western and southeastern United States (McMeeking et al., 2009).

The focus of this paper is the hygroscopic properties of biomass smoke measured during FLAME 2006. Quantifying the behavior of aerosols with respect to changing relative humidity (RH) is necessary for accurately estimating their role in climate forcing (Hansen et al., 2005) visibility degradation (Malm et al., 2005), cloud nucleating ability (Vestin et al., 2007; Petters et al., 2009), and health effects (Naeher et al., 2007). One description of the hygroscopic response of a particle is the diameter growth factor, GF, defined as the ratio of particle diameter at a specific relative humidity to the dry particle diameter $\left(\mathrm{GF}=D_{p(\mathrm{RH})} / D_{p(\mathrm{dry})}\right)$. However, estimating the effects of $\mathrm{RH}$ on aerosol radiative properties requires additional information, such as changes in particle mass, composition, size, shape and morphology as a function of RH, as these properties also affect the amount of light scattered by a particle. The humidification factor, $f(\mathrm{RH})$, describes changes in particle light scattering as a function of $\mathrm{RH}$ and is defined as the ratio of light scattering coefficients $\left(b_{\mathrm{sp}}\right)$ of humidified to dry aerosols $\left(f(\mathrm{RH})=b_{\mathrm{sp}(\mathrm{RH})} / b_{\mathrm{sp}(\mathrm{dry})}\right)$. A computed $f(\mathrm{RH})$ value for a pure, spherical inorganic salt particle composed of ammonium sulfate with a mass mean diameter of $0.4 \mu \mathrm{m}$ and geometric standard deviation of 1.9 is 3.1 at $80-85 \% \mathrm{RH}$, implying that these humidified particles scatter three times as much light as compared to dry conditions. An experimental humidification factor is typically determined by parallel measurements of light scattering coefficients under dry and humidified conditions (e.g. Day et al., 2000; Malm et al., 2003).
Previous results of $f(\mathrm{RH})$ for biomass smoke particles demonstrate a wide range of estimates. Comparisons of $f(\mathrm{RH})$ from various studies is complicated by the fact that the definitions of "dry" and "humidified" vary per study. Typically, humidified RH values range from $80-90 \%$, and although dry RH often range between 10-30\%, particles may still absorb or retain water at RH values considered "dry". Day et al. (2006) summarized $f(\mathrm{RH})$ values for a variety of locations and platforms, including aircraft, ground-based and laboratory studies. Observations of $f(\mathrm{RH})$ ranged from 1.01 to $2.1(\mathrm{RH}=80-90 \%)$ for ambient smoke; the same range of $f(\mathrm{RH})$ was observed for measurements in combustion facilities (Day et al., 2006; Lewis et al., 2009). The range of results undoubtedly was due to the range of RH values, the variety of fuel types and conditions, chemical composition of the smoke and the degree of aging and processing in the atmosphere. For example, smoke sampled in association with regional haze could be significantly mixed with inorganic species in the atmosphere that could alter hygroscopic properties of the particles (Li et al., 2003; Pósfai et al., 2003; Semeniuk et al., 2007; Zhang et al., 2008; Khalizov et al., 2009). In fact, Malm et al. (2005) found that $f(\mathrm{RH})$ for days-old smoke in Yosemite National Park CA increased from 1.2 to $\sim 2.0$ as the ratio of organic carbon mass to ammonium sulfate mass decreased. Laboratory measurements of $f(\mathrm{RH})$ for young (minutes- to hours-old) smoke reported by Day et al. (2006) were 1.01-1.76 (RH=80-90\%), demonstrating a significant range in the hygroscopic properties of unprocessed young smoke. Comprehensive measurements performed during FLAME 2006 study allowed us to investigate the range of $f(\mathrm{RH})$ for young biomass smoke in the laboratory, as well as model $f(\mathrm{RH})$ as a function of $\mathrm{RH}$.

Modeling of aerosol humidification factors requires predicting changes in aerosol physical and optical properties as a function of RH and aerosol water content. Thermodynamic equilibrium models such as the Extended Aerosol Inorganic Model (E-AIM) (Clegg et al., 1998) allow for the prediction of aerosol water content as a function of RH. Aerosol water content for an aerosol mixture can be computed using the Zdanovskii-Stokes-Robinson (ZSR) approach (Stokes and Robinson, 1966) wherein the amount of water associated with a mixture of compounds is the sum of the water content from the individual species. Computing changes in aerosol size (GF), physical and optical properties as a function of RH is straightforward once the aerosol water content is known. Mie theory is used to compute light scattering coefficients for spherical particles as a function of changing particle size and optical properties. We modeled $f(\mathrm{RH})$ by applying thermodynamic models and Mie theory to aerosol chemical composition and size distributions measured during the FLAME 2006 study.

This manuscript presents measured and modeled $f(\mathrm{RH})$ estimates for young biomass smoke generated in controlled laboratory burns of different biomass fuels. These results are noteworthy because $f(\mathrm{RH})$ was measured in conjunction 
with particle size, bulk $\mathrm{PM}_{2.5}$ composition and morphology measurements. Combining all of these data sets in a modeling framework provided for the interpretation of aerosol hygroscopicity for very young, unprocessed (by the atmosphere) smoke. The manuscript is organized in the following way. Following the introduction, Sect. 2 describes the experiments conducted during FLAME 2006, including light scattering coefficient measurements (2.1), chemical composition (2.2), size distributions (2.3), scanning electron microscopy (2.4) and particle diameter growth factors (2.5). Section 3 provides a description of the modeling technique for computing $f(\mathrm{RH})$. Results are discussed in Sect. 4 and include reports of uncertainties and sensitivity studies. A summary is provided in Sect. 5 .

\section{Experimental methods}

Controlled burns and measurements were conducted at the United States Forest Service Rocky Mountain Research Station Fire Sciences Laboratory in Missoula MT from 21 May to 9 June 2006. Details describing the facility and experimental protocols have been reported elsewhere (e.g. Day et al., 2006; Chen et al., 2006; Chakrabarty et al., 2006; McMeeking et al., 2009; Petters et al., 2009; Lewis et al., 2009; Carrico et al., 2010; Levin et al., 2010). Aerosol and gas-phase measurements were performed after the chamber was filled with smoke and instruments sampled smoke directly. A measured quantity of biomass (approximately $200 \mathrm{~g}$ ) was burned on a continuously weighed platform in the middle of the chamber. Fuels were ignited with a propane torch at the edge of the fuel, resulting in a flame front propagating through the fuel and both flaming and smoldering conditions occurring simultaneously. The fire was allowed to extinguish naturally and the measurements continued for approximately two hours. Typically three to four burns were performed a day. In this manuscript, we present results from fourteen fuels.

A thorough discussion of fuel types and their origin is provided by McMeeking et al. (2009). We grouped the fuels into four main categories. The first category, "Forest/Pine", included ponderosa pine, lodgepole pine and southern pine. The second category, "Brush", included southern California chamise, southern California manzanita, Utah juniper, Utah sage and rabbitbrush, and southern California ceanothus. "Southeastern/Tropical", the third category, included Puerto Rico fern, Puerto Rico wood, and southeastern wax myrtle. A final category of "Other" included ponderosa pine duff, Alaskan duff and lignin. A combination of woody material, needles and leaves were burned for each type, except for the duff fuels which included the decayed biomass on the forest floor as well as the top layer of the soil. The fuel was dried before burning if it did not dry out sufficiently during shipping; fuel moisture contents were reported by McMeeking et al. (2009).

\subsection{Light scattering coefficients}

Two nephelometers (model M903, wavelength of $530 \mathrm{~nm}$, Radiance Research Inc., Seattle, Washington) measured light scattering coefficients. The experimental design was similar to that used in a previous FLAME experiment (Day et al., 2006) and described in detail by Day et al. (2000). Both nephelometers sampled through identical plumbing that was connected to a $\mathrm{PM}_{2.5}$ cyclone (URG, Chapel Hill, North Carolina) and a sampling inlet that allowed for the control of relative humidity. RH and temperature were monitored at the entrance and exit of the nephelometers using hygroclip sensors (Rotronic Instruments (UK) LTD, West Sussex, UK) with a reported accuracy of $\pm 1.5 \% \mathrm{RH}$ at $23^{\circ} \mathrm{C}$. The $\mathrm{RH}$ sensors were calibrated against a dew point hygrometer plus RTD dry bulb temperature sensor (General Eastern Optica, Williston, Vermont) interfaced to a humidity generator (Model 2000, Kaymont, Huntington Station, New York) with reference probes calibrated using standard salt solutions. An error of $\pm 3 \%$ was estimated to reflect uncertainty in RH inside the nephelometer due to temperature fluctuations. Also, $\mathrm{RH}$ at the inlet and outlet of the nephelometer can vary due to heating in the nephelometer chamber. A small change in temperature $\left(\sim 1^{\circ}\right)$ can result in a significant change in $\mathrm{RH}$ at high RH ( $\sim 5 \%$ at 95\% RH) (Day et al., 2000). Although the temperature and RH were monitored at the inlet and outlet of the nephelometer, the exact $\mathrm{RH}$ and temperature inside the instrument may be slightly different. Therefore we used the average RH of the inlet and outlet sensor to represent conditions in the nephelometer chamber. The sample RH was controlled using diffusion tubes (Perma Pure LLC, Toms River, New Jersey).

Calibrations of the nephelometers with dry, filtered air and SUVA (HFC 134a) span gas were performed daily. The filtered air was used as a zero-point calibration and SUVA was used as a high calibration point. During periods of low RH $(<25 \%)$, discrepancies in $b_{\mathrm{sp}}$ values of $2-5 \%$ between the two nephelometers were observed (humidified nephelometer was biased high) but were within expected uncertainties (Anderson et al., 1996). Data from the humidified nephelometer were normalized to the dry nephelometer data using linear regression equations derived from the comparisons of data during dry conditions. For burns with no data corresponding to $\mathrm{RH}<25 \%$ for both instruments, corrections from an experiment earlier or later in the same day were applied. The sample RH of the dry nephelometer measurement was maintained between $20-25 \%$. After the biomass was ignited, the RH that corresponded to the humidified nephelometer was increased from $20-25 \%$ to over $80 \%$ over a period of one to two hours and the light scattering coefficients were measured as the aerosols were humidified. Values of $b_{\mathrm{sp}}, \mathrm{RH}$ and temperature were logged on a 5 -second time interval.

Uncertainties in $b_{\mathrm{sp}}$ and $f(\mathrm{RH})$ were computed by propagating errors derived from calibration data following the procedure detailed in Day et al. (2006). Uncertainties in 
$b_{\mathrm{sp}}$ derived from calibration data (one standard deviation) were typically $5-8 \%$. Comparisons of the normalized data from ten burns from both nephelometers during periods corresponding to low RH $(<25 \%)$ are shown in Fig. 1. Error bars reflected that the measurement uncertainty accounted for differences between the two instruments and no additional biases in the data were observed. The uncertainty in $f(\mathrm{RH})$ was computed by propagating the calibration and normalization uncertainties in $b_{\text {sp }}$ and was approximately \pm 0.08 or less for all burns. We estimated that background aerosols may be contributing at most 0.03 to measured $f(\mathrm{RH})$ by assuming all of the $b_{\mathrm{sp}}$ measured during the chamber vents was due to ammonium sulfate. This contribution was likely an overestimate and well within our experimental uncertainty.

\subsection{Chemical composition}

The IMPROVE (Interagency Monitoring of Protected Visual Environments) network sampler (Malm et al., 2004) was used to collect smoke particulate matter for $\mathrm{PM}_{2.5}$ chemical speciation and gravimetric mass analysis. The IMPROVE sampler consists of four independent modules; the three used during FLAME were equipped with a $2.5 \mu \mathrm{m}$ cyclone. Module A consisted of a Teflon filter that was analyzed for gravimetric fine $\left(\mathrm{PM}_{2.5}\right)$ mass and elements with atomic number $\geq 11(\mathrm{Na})$ and $\leq 82(\mathrm{~Pb})$ by XRF (X-ray florescence). Ion concentrations were determined using ion chromatography from samples obtained from a nylon filter in module B. Module C utilized quartz fiber filters for sample collection from which carbon was analyzed using thermal optical reflectance (TOR) techniques to separate organic carbon (OC) from light-absorbing carbon (LAC) (Chow et al., 2007). We assumed that the aerosols were internally mixed and composed of inorganic salt species $\left(\mathrm{KCl}, \mathrm{K}_{2} \mathrm{SO}_{4}, \mathrm{KNO}_{3}\right.$, $\left(\mathrm{NH}_{4}\right)_{2} \mathrm{SO}_{4}, \mathrm{NH}_{4} \mathrm{Cl}$ and $\mathrm{NaCl}$ ), carbon (POM, particulate organic matter, and $\mathrm{LAC})$ and soil $\left(\mathrm{Al}_{2} \mathrm{O}_{3}\right.$ and $\left.\mathrm{CaO}\right)$ following Levin et al. (2010). Potassium salts are commonly observed in biomass smoke emissions (e.g. Pósfai et al., 2003; Freney et al., 2009; Semeniuk et al., 2007; Lewis et al., 2009) and in fact potassium and chloride were the most abundant ions from the emissions from most of these burns. Organic carbon was converted to POM by multiplying OC by a molecular carbon to organic carbon multiplier.

The molecular carbon to organic carbon multiplier is necessary to account for other elements associated with the organic carbon composition (Turpin and Lim, 2001). Values can range from 1 to greater than 2 depending on sources and atmospheric processing (Turpin and Lim, 2001; Russell, 2003; El-Zanan et al., 2005; Malm and Hand, 2007). We derived estimates of the multiplier using a mass balance approach by forcing closure between measured $\mathrm{PM}_{2.5}$ gravimetric and reconstructed mass within $5 \mu \mathrm{g} \mathrm{m}^{-3}$ (typically $<3 \%$ of mass). The values obtained ranged from 1.4 to 2.5 , with an average and one standard deviation of $1.7 \pm 0.3$, depending on the burn. While we recognize these values

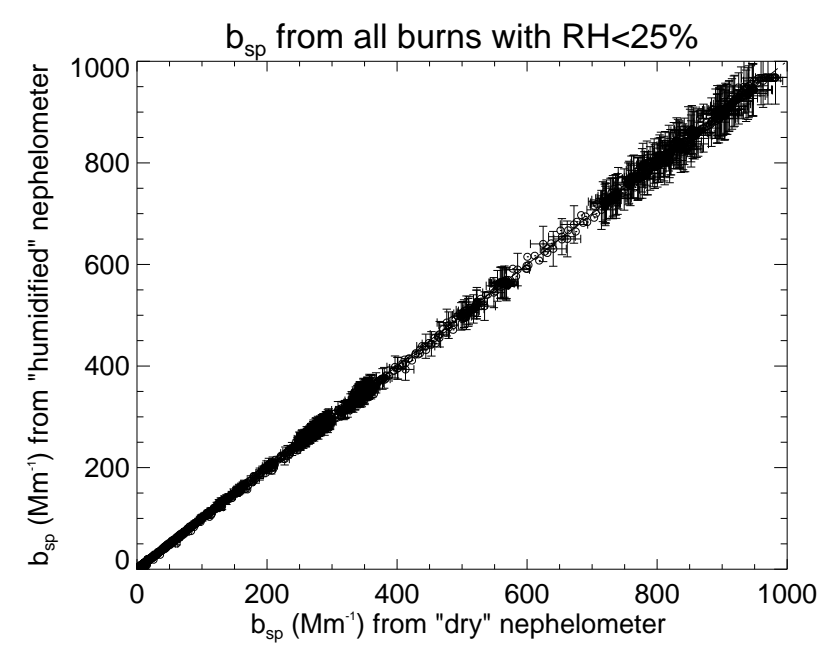

Fig. 1. Comparison of dry $(\mathrm{RH}<25 \%) b_{\mathrm{sp}}\left(\mathrm{Mm}^{-1}\right.$, wavelength of $530 \mathrm{~nm}$ ) for ten burns.

were subject to uncertainties inherent in the mass balance approach (e.g. El-Zanan et al., 2005; Malm and Hand, 2007), the derived estimates were consistent with previous literature for biomass burning samples (Reid et al., 2005a; Malm et al., 2005; Turpin and Lim, 2001). Further discussion of the multiplier and the sensitivity of $f(\mathrm{RH})$ will be presented in Sect. 4.

\subsection{Particle size distributions}

Particle number concentrations as a function of size were measured using a differential mobility particle sizer (DMPS, TSI, Minneapolis, Minnesota) that included a differential mobility analyzer (TSI 3081) and associated condensation particle counter (TSI 3785). A total of 24 bins were used with a diameter range of $0.04<D_{\mathrm{p}}<0.65 \mu \mathrm{m}$. The sample was not dried because the RH of the burn chamber was typically lower than $20 \%$. More details regarding the size distribution measurements were provided by Levin et al. (2010). From the $10 \mathrm{~min}$ dry aerosol number distributions we computed an average size distribution over the entire $(\sim 2 \mathrm{~h})$ burn. In some cases the size distributions evolved over the burn duration, in other cases it remained fairly stable (see Levin et al., 2010). Results from both McMeeking et al. (2009) and Levin et al. (2010) indicated that the size distributions were dominated by accumulation mode particles. Sensitivity of $f(\mathrm{RH})$ to the variability of the size distribution will be discussed in Sect. 4.

Mass concentrations were derived by integrating the volume size distributions measured by the DMPS and multiplying by a mixture density derived from the chemical composition data for each burn (see Sect. 3). Comparisons between DMPS reconstructed mass and gravimetric fine mass from the IMPROVE samplers showed an overestimation of 
the DMPS mass by a factor of six in some cases. Recall that the IMPROVE sampler is a $\mathrm{PM}_{2.5}$ sampler while the DMPS sampled particles up to $0.65 \mu \mathrm{m}$ in diameter, so it was expected that the DMPS would actually underestimate particulate mass given the differences in the upper size limits. Previous studies have shown that when using the DMPS to sample non-spherical particles sizing discrepancies can occur (e.g. Krämer et al., 2000; Schneider et al., 2006; Khalizov et al., 2009). As we will show in Sect. 4, many of the burns yielded fractal particles containing long-chains of soot as observed in scanning electron microscope (SEM) images. In fact, the largest discrepancies in mass corresponded to samples dominated by aggregated soot chains. To account for the effects of non-sphericity on size distributions, we used the dynamic shape factor, $\chi$, defined as the ratio of the actual resistance force of a non-spherical particle to the resistance force of a sphere having the same velocity and volume (Hinds, 1999). For our application, $\chi$ relates the equivalent diameter $\left(D_{\mathrm{p}}\right)$ to the mobility diameter $\left(D_{\mathrm{m}}\right)$ by Eq. (1):

$$
\chi=\frac{D_{\mathrm{m}}}{D_{\mathrm{p}}}
$$

A shape factor of $\chi=1$ corresponds to a sphere and for irregularly shaped particles or agglomerates it can be as high as 2 or more (Baron and Willeke, 1993). Shape factors were derived by dividing the DMPS-derived mass by the IMPROVE gravimetric fine mass and taking the cubed root. The values ranged from 0.8 to 1.8 with an average and one standard deviation of $1.3 \pm 0.3$. These shape factors were in the range reported by Krämer et al. (2000) for sodium chloride crystals, and for biomass smoke (Schneider et al., 2006; Gwaze et al., 2006). The highest values corresponded to the burns with agglomerates of soot chains viewed by SEM images, consistent with observation made earlier of the comparisons with the largest discrepancies in mass. There were three cases when $\chi<1$ (ponderosa pine duff, Alaska duff and ceanothus); values less than one are physically unrealistic and reflect the uncertainties in the estimates. For example, values of $\chi$ obviously were sensitive to the derived densities used to compute mass, as well as any discrepancies in the volume or mass concentrations. We adjusted the size distributions by dividing bin diameters by the shape factors derived for each burn. Sensitivity of $f(\mathrm{RH})$ to the application of the shape factor will be discussed in Sect. 4 .

\subsection{Scanning electron microscopy analysis}

Particles were collected onto transmission electron microscope filmed grid substrates (Carbon type B on $\mathrm{Cu} 400$ mesh grids, Ted Pella Inc. Redding, California) for scanning electron microscopy analysis using a rotating cascade impactor (MOUDI, model 110, MSP, Inc.). Scanning electron microscopy imaging of collected samples and X-ray microanalysis of particles were performed at the Environmental Molecular Sciences Laboratory (Richland, WA), using a FEG XL30 digital scanning electron microscope (FEI, Inc.) equipped with an energy dispersed X-ray (EDX) spectrometer (EDAX, Inc.). Specific details of the SEM/EDX analysis of particles deposited onto filmed grid substrates are described elsewhere (Laskin et al., 2006, and references therein).

\subsection{Growth Factors (GF)}

Particle diameter growth factors (GF) were measured using a hygroscopic tandem differential mobility analyzer (HTDMA). The HTDMA includes a DMA that selected a nearly-monodisperse aerosol sample (in this case, particles of $100 \mathrm{~nm}$ mobility diameter), followed by a conditioning system that subjected the particles to controlled water subsaturated environment (Rader and McMurry, 1986). A second DMA classifier measured the size distributions of humidified particles. Measurements were made at eight RH values ranging from $40 \%$ to $95 \%$. A detailed description of the experimental protocol was reported by Carrico et al. (2008, 2010). All experiments were conducted such that particles were initially dry $(\mathrm{RH}<15 \%)$ and then exposed to a preset higher RH before being measured by the second DMA. Growth factors were defined as the ratio of the humidified diameter to the dry diameter. The estimated uncertainty in GF was 0.02 for spherical particles, combined with an estimated uncertainty in RH of $2 \%$ (Carrico et al., 2010).

\section{Modeled Humidification Factors $(f(\mathbf{R H}))$}

Modeling of humidification factors $(f(\mathrm{RH}))$ as a function of RH required knowledge of the changes in particle composition, size and optical properties due to changes in aerosol water content. Thermodynamic equilibrium models required aerosol chemical composition data and provided aerosol water content as a function of RH. Aerosol water content was then used to calculate changes in particle size (GF), mass and composition. Particle light scattering coefficients were computed by applying Mie theory to measured size distributions while incorporating variations in particle size and refractive index as a function of RH.

We used the E-AIM inorganic thermodynamic equilibrium model III (Extended Aerosol Inorganic Model, Clegg et al., 1998, http://www.aim.env.uea.ac.uk/aim/aim.php) to calculate aerosol water content for inorganic aerosols by incorporating measured mass concentrations of solid phase species. E-AIM modeled the system of ions including hydrogen, ammonium, sodium, sulfate, nitrate and chloride as well as water. It can be run in several configurations. Species can be partitioned into solid, liquid or gaseous phases. Because EAIM does not include potassium salts, we assumed all of the potassium was sodium and adjusted these concentrations to achieve a charge balance (S. L. Clegg, personal communication, 2009). We modeled both deliquescence and metastable equilibrium. The model was run in parametric mode that 
allowed for the varying of RH from 10-99\% at a temperature of $298.15 \mathrm{~K}$ only. While E-AIM provided an option for hygroscopic growth from organic species, we did not apply it in this application, as we were interested in the role of inorganic species.

The diameter growth factor, GF, for the inorganic aerosol mixture was computed using Eq. (2).

$\mathrm{GF}=\left[\left(M_{\mathrm{RH}} / \rho_{\mathrm{RH}}\right) /\left(M_{\mathrm{dry}} / \rho_{\mathrm{dry}}\right)\right]^{1 / 3}$

The dry mass and density are $M_{\text {dry }}$ and $\rho_{\text {dry }}$, respectively. The humidified mass $\left(M_{\mathrm{RH}}\right)$ is the sum of the dry mass and the derived aerosol water content as a function of RH from E-AIM. The humidified density $\left(\rho_{\mathrm{RH}}\right)$ was computed using volume-mixing rules (Hasan and Dzubay, 1983; Ouimette and Flagan, 1982) shown in Eq. (3).

$\bar{\rho}^{-1}=\sum_{i} \frac{X_{i}}{\rho_{i}}$

The mass fraction for a given species $(i)$ is $X_{i}$ and the density is $\rho_{i}$. The values of $\rho_{i}$ for each species are listed in Table 1. The POM concentrations used in this calculation corresponded to the values derived from mass closure. In the case of dry mixture density, the mass fractions and densities were summed over each individual dry species. In the case of the humidified density, the dry mixture density and water density were summed. Dry mixture densities (inorganic salts + carbon + soil) ranged from $1.42-1.95 \mathrm{~g} \mathrm{~cm}^{-3}$ for all of the burns, with an average and one standard deviation of $1.6 \pm 0.2 \mathrm{~g} \mathrm{~cm}^{-3}$. The dry densities for each burn are listed in Table 2. These values are somewhat higher than the prior estimates of biomass burning aerosol densities of 1.2$1.4 \mathrm{~g} \mathrm{~cm}^{-3}$ (Reid et al., 2005a) but are consistent with Levin et al. (2010).

The mixture GF was computed using Eq. (4) following Malm and Kreidenweis (1997) who invoked the ZdanovskiiStokes-Robinson (ZSR) assumption (Stokes and Robinson, 1966).

$\mathrm{GF}^{3}=\frac{\rho_{\mathrm{dry}}}{\rho_{\mathrm{RH}}}\left(\sum_{i} X_{i} \frac{\rho_{\mathrm{RH}, i}}{\rho_{\mathrm{dry}, i}}\left(\mathrm{GF}_{i}\right)^{3}\right)$

The growth factor for species $i$ at a given $\mathrm{RH}$ is $\mathrm{GF}_{i}$. The mixture dry density is $\rho_{\text {dry }}$ and the humidified mixture density is $\rho_{\mathrm{RH}}$. The species included were inorganic salts, carbon (POM+LAC) and soil. The GF values for POM, LAC and soil were set equal to one and held constant with $\mathrm{RH}$, and their densities were fixed at the values listed in Table 1. GF curves were computed for both deliquescence and metastable equilibrium. Both curves were normalized to one $(\mathrm{GF}=1)$ at the RH corresponding to the dry HTDMA measurements. This normalization resulted in suppression of the metastable curve below the deliquescence curves at high RH. This suppression was most pronounced for cases when metastable
Table 1. Density and refractive index for the species used to model aerosol optical and physical properties. OC and LAC correspond to organic carbon and light absorbing carbon, respectively. Refractive indices correspond to a wavelength of $530 \mathrm{~nm}$.

\begin{tabular}{lrr}
\hline Species & Density $\left(\mathrm{g} \mathrm{cm}^{-3}\right)$ & Refractive index \\
\hline $\mathrm{KCl}$ & 1.76 & $1.53^{\mathrm{a}}$ \\
$\mathrm{K}_{2} \mathrm{SO}_{4}$ & 1.83 & $1.51^{\mathrm{a}}$ \\
$\mathrm{KNO}_{3}$ & 1.78 & $1.47^{\mathrm{a}}$ \\
$\mathrm{NH}_{4} \mathrm{Cl}$ & 1.8 & $1.41^{\mathrm{a}}$ \\
$\left(\mathrm{NH}_{4}\right)_{2} \mathrm{SO}_{4}$ & 1.725 & $1.55^{\mathrm{b}}$ \\
$\mathrm{Al}_{2} \mathrm{O}_{3}$ & 2.165 & $1.54^{\mathrm{a}}$ \\
$\mathrm{CaO}$ & 1.984 & $1.49^{\mathrm{a}}$ \\
$\mathrm{OC}$ & 1.4 & $1.55^{\mathrm{b}, \mathrm{c}}$ \\
$\mathrm{LAC}$ & 2 & $1.96-0.66 i^{\mathrm{b}}$ \\
\hline
\end{tabular}

${ }^{a}$ Lide et al. (2008) ${ }^{\mathrm{b}}$ Seinfeld and Pandis (1998) ${ }^{\mathrm{c}}$ Dick et al. (2000)

equilibrium predicted considerable water at low RH conditions. In the absence of the normalization the two curves agreed above the deliquescence RH.

Comparisons of modeled and measured GF are shown for weak to non-hygroscopic smoke (ponderosa pine) and for a more hygroscopic smoke (sage/rabbit brush) in Figs. 2 and 3, respectively. The measured GF values corresponded to $100 \mathrm{~nm}$ diameter particles only, while the modeled GF were derived from IMPROVE $\mathrm{PM}_{2.5}$ bulk mass concentrations. Dry RH for the measured and modeled GF was the same. The modeled GF for smoke particles from burns of ponderosa pine (Fig. 2) were flat as a function of RH and showed no significant difference between both methods (labeled "metastable" and "deliquescence"). The measured GF fell slightly above these curves (outside of experimental uncertainty, 0.02) but did not demonstrate any measureable growth with increased RH. In contrast, the modeled GF curves for sage/rabbit brush increased continuously with $\mathrm{RH}$ for the metastable curve while the deliquescence curve showed additional water uptake around $70 \% \mathrm{RH}$. The differences between the modeled curves at high $\mathrm{RH}$ reflect the normalization discussed earlier. The measured GF values fell between these two curves for $\mathrm{RH}>85 \%$, suggesting the modeled curves were representing the hygroscopic properties of particles during this burn. We present these comparisons to demonstrate the typical agreement observed between measured and modeled GF for each burn; more details regarding measured GF can be found in Carrico et al. (2010).

The GF curves were applied to the measured size distributions to compute aerosol light scattering coefficients as a function of RH. Refractive indices $\left(\bar{n}=m-k_{i}\right)$ were calculated using volume-weighted mixing rules shown in Eq. (5) (Ouimette and Flagan, 1982; Hasan and Dzubay, 1983). 
Table 2. Measured and derived smoke characteristics for biomass fuels burned during FLAME 2006. Shape factors $(\chi)$ were derived from DMPS data (see text), POM/OC refers to the multiplier used to convert organic carbon (OC) to particulate organic matter (POM). Density and refractive index correspond to the dry mixed aerosol. "Carbon mass fraction" refers to the sum of POM and light absorbing carbon (LAC), while the "inorganic" refers to salts only and is divided by the sum of OC and LAC. Measured $f(\mathrm{RH})$ is reported for $\mathrm{RH}=80-85 \%$, with dry $\mathrm{RH}=20-25 \%$, wavelength of $530 \mathrm{~nm}$ and experimental uncertainty of \pm 0.08 . The $f(\mathrm{RH})$ results from the E-AIM model for deliquescence ("del") and metastable equilibrium ("meta") also refer to $80-85 \% \mathrm{RH}$ and the same wavelength. Fuel names are listed in the first column and separated into fuel types.

\begin{tabular}{|c|c|c|c|c|c|c|c|c|c|}
\hline Fuel & $\begin{array}{l}\text { Shape Factor } \\
(\chi)\end{array}$ & $\mathrm{POM} / \mathrm{OC}$ & $\begin{array}{l}\text { Density } \\
\left(\mathrm{g} \mathrm{cm}^{-3}\right)\end{array}$ & $\begin{array}{l}\text { Refractive Index } \\
\quad(n=m-k i)\end{array}$ & $\begin{array}{l}\text { Inorganic/ } \\
(\mathrm{OC}+\mathrm{LAC})\end{array}$ & $\begin{array}{l}\text { Carbon mass } \\
\text { fraction }(\%)\end{array}$ & $\begin{array}{c}f(\mathrm{RH}) \\
(80-85 \%)\end{array}$ & $\begin{array}{c}f(\mathrm{RH}) \\
\text { model- (del) }\end{array}$ & $\begin{array}{c}f(\mathrm{RH}) \\
\text { model- (meta) }\end{array}$ \\
\hline \multicolumn{10}{|l|}{ Forest/Pine Type } \\
\hline 1. Ponderosa Pine & 1.0 & 1.6 & 1.47 & $1.59-0.07 i$ & 0.02 & 98 & 1.00 & 1.03 & 1.03 \\
\hline 2. Lodgepole Pine & 1.2 & 1.5 & 1.45 & $1.58-0.05 i$ & 0.03 & 98 & 1.02 & 1.03 & 1.03 \\
\hline 3. Southern Pine & 1.1 & 1.6 & 1.47 & $1.60-0.07 i$ & 0.03 & 98 & 1.07 & 1.04 & 1.03 \\
\hline \multicolumn{10}{|l|}{ Brush Type } \\
\hline 4. Chamise & 1.5 & 1.9 & 1.87 & $1.71-0.26 i$ & 0.42 & 70 & 1.58 & 1.53 & 1.41 \\
\hline 5. Chamise (repeat) & 1.6 & 1.4 & 1.86 & $1.69-0.23 i$ & 0.44 & 68 & 1.45 & 1.53 & 1.39 \\
\hline 6. Juniper & 1.8 & 2.5 & 1.84 & $1.79-0.39 i$ & 0.14 & 87 & 1.14 & 1.22 & 1.17 \\
\hline 7. Sage/Rabbit Brush & 1.8 & 1.8 & 1.95 & $1.70-0.24 i$ & 0.67 & 58 & 1.81 & 1.88 & 1.63 \\
\hline 8. Manzanita & 1.7 & 1.6 & 1.77 & $1.69-0.24 i$ & 0.27 & 78 & 1.34 & 1.42 & 1.35 \\
\hline 9. Ceanothus & 0.9 & 1.5 & 1.51 & $1.56-0.02 i$ & 0.24 & 84 & 1.15 & 1.31 & 1.16 \\
\hline \multicolumn{10}{|l|}{ S.E. US/Tropical } \\
\hline 10. Puerto Rico Fern & 1.1 & 1.6 & 1.47 & $1.57-0.04 i$ & 0.15 & 90 & 1.07 & 1.31 & 1.22 \\
\hline 11. Puerto Rico Wood & 1.0 & 1.9 & 1.53 & $1.63-0.12 i$ & 0.10 & 93 & 1.06 & 1.14 & 1.11 \\
\hline 12. Wax Myrtle & 1.1 & 1.9 & 1.61 & $1.60-0.09 i$ & 0.41 & 74 & 1.34 & 1.88 & 1.58 \\
\hline \multicolumn{10}{|l|}{ Other } \\
\hline 13. Ponderosa Pine Duff & 0.9 & 1.4 & 1.44 & $1.57-0.04 i$ & 0.03 & 97 & 1.04 & 1.04 & 1.03 \\
\hline 14. Alaskan Duff & 0.8 & 1.6 & 1.42 & $1.56-0.012 i$ & 0.03 & 98 & 1.07 & 1.03 & 1.02 \\
\hline 15. Lignin & 1.3 & 1.5 & 1.56 & $1.66-0.17 i$ & 0.02 & 98 & 0.99 & 1.05 & 1.04 \\
\hline
\end{tabular}

$\bar{n}=\bar{\rho} \sum_{j} \frac{X_{j} m_{j}}{\rho_{j}}-\bar{\rho} \sum_{j} \frac{X_{j} k_{j}}{\rho_{j}} \mathrm{i}$

Real $\left(m_{j}\right)$ and imaginary $\left(k_{j}\right)$ parts of the refractive indices for individual species are listed in Table 1. Here we sum over species $j$ to avoid confusion with the imaginary part of the refractive index. The mixture density was computed using Eq. (3). The real part of the dry refractive indices ranged from 1.56 to 1.79 with an average and one standard deviation of $1.63 \pm 0.07$. The imaginary part ranged from $0.012-0.39$ with an average and one standard deviation of $0.14 \pm 0.11$. LAC was the only species assumed to absorb light. Some organic aerosol species may also absorb light (e.g., Kirchstetter et al., 2004; Hand et al., 2005; Hoffer et al., 2006) but the effect was not included here. Values corresponding to each fuel are listed in Table 2. These values are consistent with previous reported estimates of biomass burning refractive indices (Reid et al., 2005b, McMeeking et al., 2005; Hungershoefer et al., 2008) and are consistent with values reported by Levin et al. (2010) for FLAME 2006 and 2007 studies. More discussion of these values can be found in Sect. 4 .

Equation (6) was used to compute light scattering coefficients for dry or humidified particles (Hand et al., 2004).

$b_{\mathrm{sp}}=\int \frac{3}{2} \frac{Q_{\mathrm{sp}}}{D_{\mathrm{pm}(\mathrm{dry})}} \mathrm{GF}^{2} \frac{d V_{\mathrm{dry}}}{d \log D_{\mathrm{p}}} d \log D_{\mathrm{p}}$

For $b_{\mathrm{sp}(\mathrm{dry})}$, the Mie scattering efficiency $\left(Q_{\mathrm{sp}}\right)$ was computed for diameters and complex refractive indices of dry

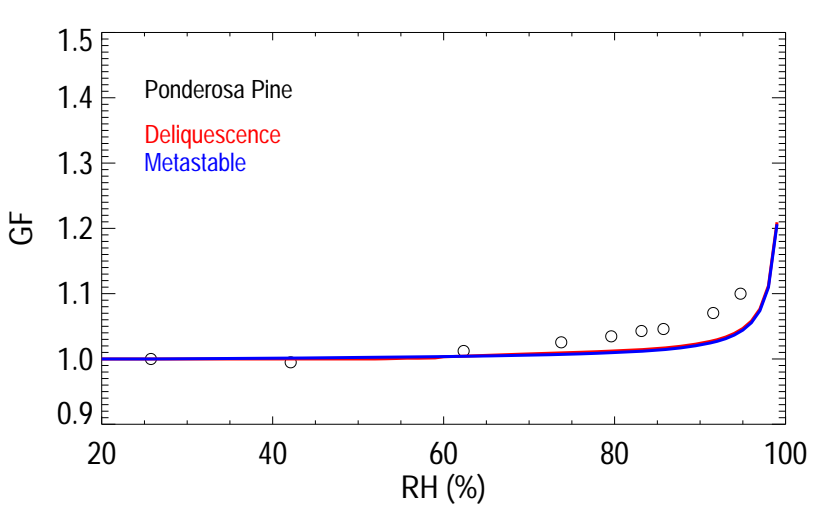

Fig. 2. Growth factors (GF) for $100 \mathrm{~nm}$ smoke particles emitted from ponderosa pine burns as a function of relative humidity $(\mathrm{RH}$, $\%)$. The GF results derived from the E-AIM model are for deliquescence and metastable equilibrium.

particles. For $b_{\mathrm{sp}(\mathrm{RH}),} Q_{\mathrm{sp}}$ was computed using diameters and complex refractive indices adjusted for water content. The dry volume size distribution is given by $d V_{\mathrm{dry}} / d \log D_{\mathrm{p}}$. Calculations were performed at a wavelength of $530 \mathrm{~nm}$. GF is the growth factor derived with the thermodynamic models described above and $D_{\mathrm{pm}(\mathrm{dry})}$ corresponds to the dry midpoint diameter of a size distribution bin. The humidification factor $f(\mathrm{RH})$ was computed by dividing $b_{\mathrm{sp}(\mathrm{RH})}$ by $b_{\mathrm{sp}(\mathrm{dry})}$ where $b_{\mathrm{sp}(\mathrm{dry})}$ corresponds to the $\mathrm{RH}$ of nephelometer 


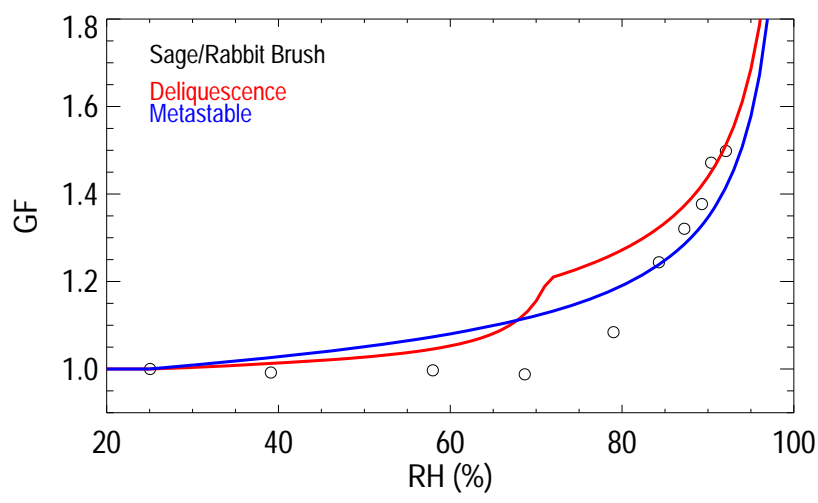

Fig. 3. Growth factors (GF) for $100 \mathrm{~nm}$ smoke particles emitted from Utah sage/rabbit brush burns as a function of relative humidity (RH, \%). The GF results derived from the E-AIM model are for deliquescence and metastable equilibrium.

measurements at $20-25 \% \mathrm{RH}$. The modeled $f(\mathrm{RH})$ curves were normalized to one at the dry nephelometer RH, similar to the GF case.

\section{Results and discussion}

\subsection{Humidification factors $(f(\mathbf{R H}))$}

The extent of agreement between measured and modeled $f(\mathrm{RH})$ values is limited by the number of simplifying assumptions required to perform the calculations. Characterizing heterogeneous, non-spherical, chemically complex particles as homogeneous internally mixed spheres of known composition, size, and water content obviously could affect how well the calculated and measured values of $f(\mathrm{RH})$ agree. The assumptions and limitations are important to keep in mind when evaluating the comparisons between modeled and measured values of $f(\mathrm{RH})$, and sensitivity to some of these assumptions will be discussed in the next section.

We present comparisons of $f(\mathrm{RH})$ values for smoke particles generated from burning of four fuel types (Forest/Pine, Brush, southeast US/Tropical and Other) and their relation to other measured smoke properties such as composition and microstructure. Comparisons of measured to modeled $f(\mathrm{RH})$ are difficult to quantify over the entire $\mathrm{RH}$ range, therefore we compared $f(\mathrm{RH})$ over $\mathrm{RH}=80-85 \%$, and we separated the comparisons between the two model estimates (metastable and deliquescence). The average modeled $f(\mathrm{RH})$ was computed for the same $\mathrm{RH}$ values over which the measurements were performed. Measured and modeled results for all of the fuels are reported in Table 2.

The $f(\mathrm{RH})$ curve corresponding to particles generated from burns of ponderosa pine is presented in Fig. 4. Ponderosa pine is representative of the other fuels in the Forest/Pine fuel category, all of which produced either weak or non-hygroscopic particles, with minimal growth observed

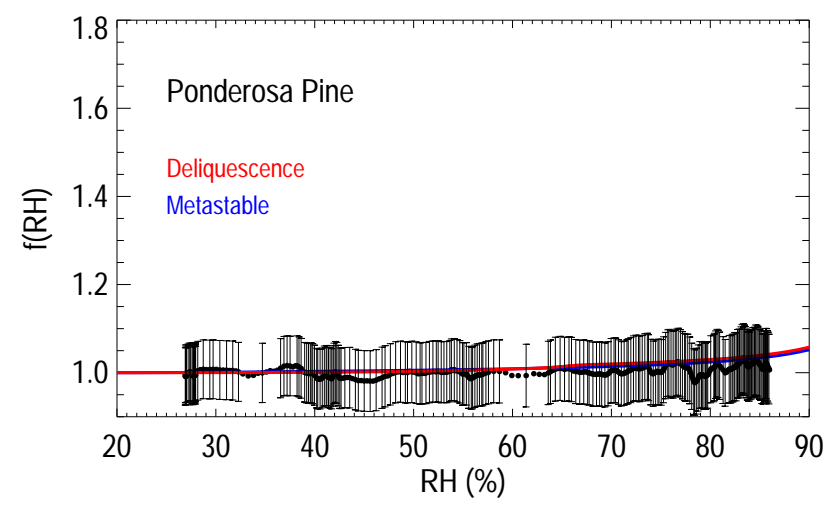

Fig. 4. Measured and modeled humidification factors $(f(\mathrm{RH}))$ as a function of relative humidity $(\mathrm{RH}, \%)$ for particles emitted from ponderosa pine burns. The $f(\mathrm{RH})$ results derived from the E-AIM model are for deliquescence and metastable equilibrium. Measurements and model calculations performed at a wavelength of $530 \mathrm{~nm}$.

above $80 \%$ (see Table 2). Values of $f(\mathrm{RH})$ for smoke from this fuel type did not exceed $1.1 \pm 0.08$ for $\mathrm{RH}=80-85 \%$. The modeled $f(\mathrm{RH})$ values agreed within experimental uncertainty for fuels of this type, with model results ranging between 1.03 and 1.04 for both deliquescence and metastable equilibrium. The modeled curves were flat over most of the $\mathrm{RH}$ range and started to increase around $95 \%$. No deliquescence behavior was observed in either measured or modeled results. Smoke particles generated from the burning of these fuels were dominated by carbon, with combined POM and LAC mass fractions of $98 \%$ or more. Inorganic salt to carbon $(\mathrm{OC}+\mathrm{LAC})$ ratios were small, typically less than 0.03 . Figure 5 shows an SEM image of particles generated in burns of ponderosa pine. Morphology of these particles was very typical for those generated in burns of the Forest/Pine type of fuels. The oily organic content of particles was largely electron-transparent and was seen in the images as dark areas that commonly contain soot inclusions, which are seen as bright fragments. X-ray microanalysis of both dark areas and bright inclusions showed almost no elements other than carbon and oxygen, which was consistent with the bulk analysis data. Additionally, DMPS-derived shape factors for these particles were fairly small (1.0-1.2), suggesting that airborne particles were nearly spherical (Table 2), which is also consistent with substantial coating of particles with oily organic material. Finally, densities ranged from 1.45$1.47 \mathrm{~g} \mathrm{~cm}^{-3}$, consistent with the dominance of POM and its density $\left(1.4 \mathrm{~g} \mathrm{~cm}^{-3}\right)$ that was assumed in the calculation. Refractive indices also reflected the dominance of POM with real values around 1.6 and imaginary parts less than 0.07 . The organic carbon multipliers were fairly low (1.5-1.6) for these young particles, as opposed to estimates reported by Malm et al. (2005) for ambient aged smoke $(\sim 1.8)$. 


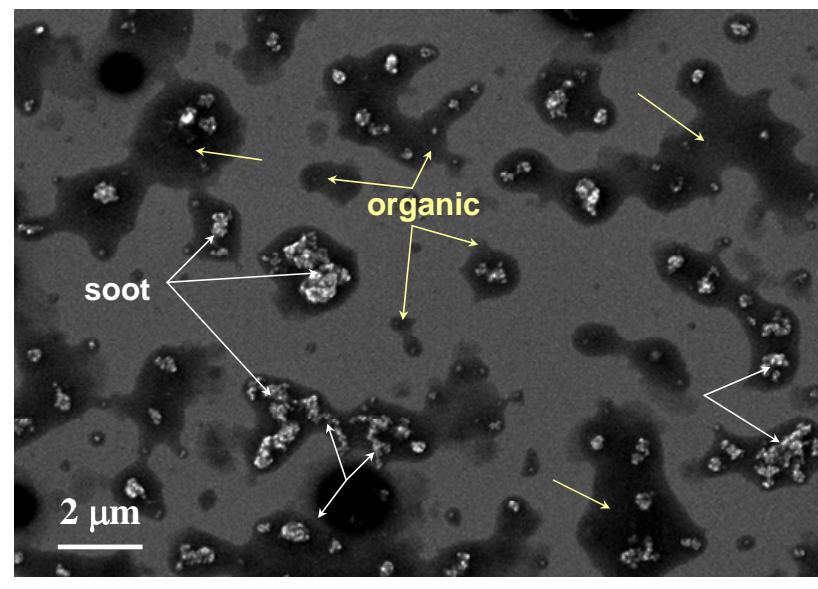

Fig. 5. Secondary electron (SE) microscopy image of smoke particles generated during the burn of ponderosa pine fuel. Typical particles are composed of soot cores coated with oily organic material (labeled). The sample was collected for the aerodynamic diameter size range between $0.32-0.5 \mu \mathrm{m}$.

Smoke particles generated in the burns of Brush fuels were significantly hygroscopic, with $f(\mathrm{RH})(80-85 \%)$ values ranging from 1.14 (juniper) to 1.81 (sage/rabbit brush). The $f(\mathrm{RH})$ curves shown in Fig. 6 for sage/rabbit brush fuel demonstrated flat growth $(f(\mathrm{RH})=1)$ until around $55 \% \mathrm{RH}$ after which the $f(\mathrm{RH})$ smoothly increased. Although within experimental uncertainty, measurements suggest possible deliquescence around $75 \% \mathrm{RH}$ while the modeled deliquescence was shifted lower by about $5 \%(70 \%)$. Both model approaches overestimated the data until $\sim 75 \% \mathrm{RH}$ when the data fell between the deliquescence and metastable curves. Above $\sim 85 \%$ the measurements were in closer agreement with the deliquescence curve. The modeled $f(\mathrm{RH}=80-85 \%)$ was 1.88 and 1.63 for the deliquescence and metastable estimates, respectively. The continuous growth observed for smoke particles from sage/rabbit brush burns was typical for fuels of this type (Lewis et al., 2009). Inorganic constituents contributed substantially to the mass of particles, with carbon mass fraction ranging from $58-87 \%$ and inorganic salt to (OC+LAC) ratios from 0.14-0.67 (Table 2). Smoke from these fuels had large shape factors, with the largest $(\chi=1.8)$ corresponding to particles from juniper burns. The large shape factors were consistent with observations from the SEM images that revealed the presence of highly fractal soot particles in the samples. The top two panels of Fig. 7 show two images of particles in the same field of view obtained using secondary electron (SE) and backscattered electron (BSE) imaging modes, respectively. Soot and organic particles are clearly seen and labeled in the SE image. Carbonaceous materials have very low backscattering efficiency. Therefore, both fractal soot and organic particle are nearly invisible in the BSE image. In contrast, higher atomic number inorganic particles and inclusions are visible in the BSE

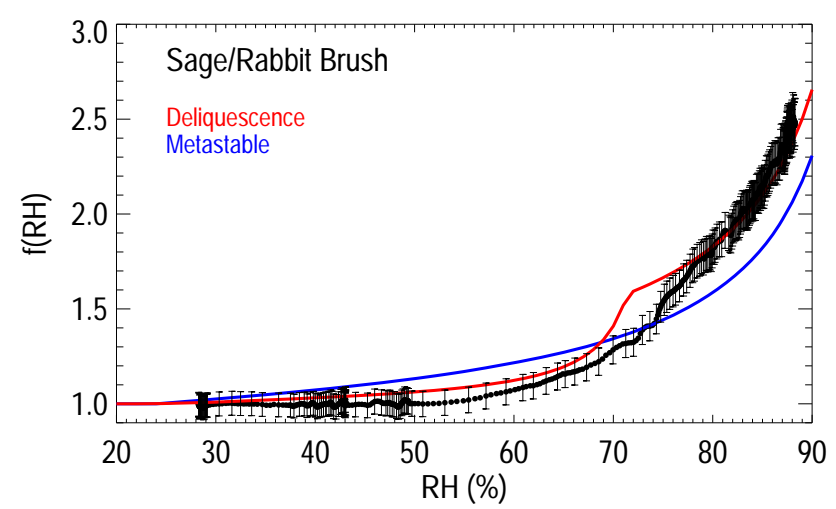

Fig. 6. Measured and modeled humidification factors $(f(\mathrm{RH}))$ as a function of relative humidity $(\mathrm{RH}, \%)$ for particles emitted from Utah sage/rabbit brush burns. The $f(\mathrm{RH})$ results derived from the E-AIM model are for deliquescence and metastable equilibrium. Measurements and model calculations performed at a wavelength of $530 \mathrm{~nm}$.

image. The bottom panel of Fig. 7 shows characteristic $\mathrm{X}$-ray spectrum of these inorganic particles indicating their mixed $\mathrm{KCl} / \mathrm{K}_{2} \mathrm{SO}_{4}$ composition. Similar observations were reported for particles sampled from chamise burns (Lewis et al., 2009) and sagebrush (Chakrabarty et al., 2006). Similarly, internally mixed soot and organic particles with inorganic species have been observed previously for ambient biomass smoke samples (e.g. Li et al., 2003; Pósfai et al., 2003; Hand et al., 2005; Semeniuk et al., 2007). OC multipliers tended to be higher for smoke particles from burns of these fuels, as did refractive indices (real and imaginary) and densities, reflecting the higher inorganic and LAC content of these fuels (see Table 2). With the exception of ceanothus, all of the fuels of this type had LAC mass fractions of $~ 30 \%$ or greater, consistent with the dominance of soot in the SEM images.

Smoke particles from the southeastern US/Tropical fuels tended to be less hygroscopic than those from the Brush type, with the values of $f(\mathrm{RH})$ at $80-85 \% \mathrm{RH}$ of 1.06 to 1.34. The data did not show any visible deliquescence and indicated continuous growth at higher RH. For all fuels of this type, the model overpredicted measured $f(\mathrm{RH})$ values at $\mathrm{RH}=80-85 \%$, and were within experimental uncertainty only for the Puerto Rico wood case. The carbon content for particles from fuels of this type ranged from $74 \%$ to $93 \%$, and the inorganic salt to $(\mathrm{OC}+\mathrm{LAC})$ ratios ranged from 0.10 to 0.41 . The shape factors, organic multipliers, densities and refractive indices for particles from this fuel type were similar but somewhat higher than for particles from burns of the Forest/Pine fuels (see Table 2). SEM images showed heterogeneity in particle microstructure for these fuels. Round particles rich in carbon and oxygen and having inorganic inclusions dominated the Puerto Rico fern and Puerto Rico wood samples. In comparison, the wax myrtle sample is abundant 

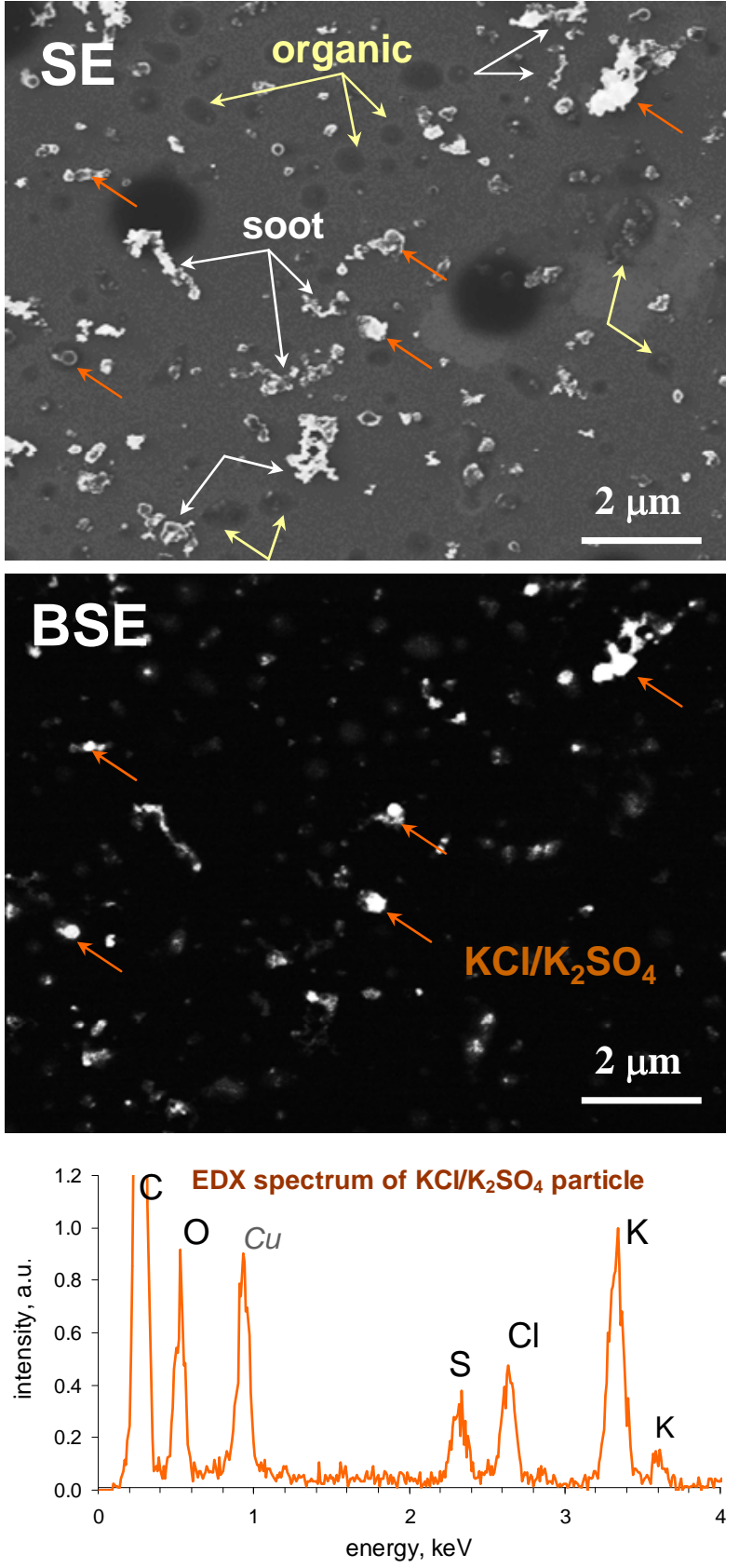

Fig. 7. Secondary electron (SE) image (top panel) and back scattered electron (BSE) microscope image (middle panel) of smoke particles generated from burns of Utah sage/rabbit brush fuel. Typical fractal soot, organic and inorganic particles are seen internally and externally mixed. Carbonaceous soot and organic constituents are invisible in the BSE image, while inorganic constituents are seen as bright spots in the BSE image. Bottom panel: characteristic energy dispersed $\mathrm{X}$-ray (EDX) spectrum of inorganic inclusions indicates their mixed $\mathrm{KCl} / \mathrm{K}_{2} \mathrm{SO}_{4}$ composition. ( $\mathrm{Cu}$ peak results from a substrate background, $\mathrm{C}$ and $\mathrm{O}$ peaks are mixed background and sample signals). Samples were collected in the $0.18-0.32 \mu \mathrm{m}$ aerodynamic diameter size range. with $\mathrm{NaCl}$ and $\mathrm{KCl}$ particles internally and externally mixed with carbon but without the oily/liquid particles seen in the ponderosa pine sample.

The final fuel type, Other, included ponderosa pine duff, Alaskan duff, and lignin. Smoke particles from these burns were weak to non-hygroscopic with $f(\mathrm{RH})(80-85 \%)$ values of 0.99 to 1.07 . The weak hygroscopic behavior observed for these particles was similar to those from the first fuel type and was indicated by very flat, smooth curves that exhibit little to no growth at high RH. Within experimental uncertainty, model estimates (both deliquescence and metastable) agreed well, with values of $f(\mathrm{RH})$ ranging from 1.02-1.05. Smoke particles from both of these fuels had high carbon mass fractions ( $>97 \%)$ and inorganic salt to (OC+LAC) ratios of 0.03 or less. The SEM images and EDX analysis of particles from burns of ponderosa pine duff showed round and irregular particles dominated by carbon and oxygen. Some particles appeared to have been flattened upon impaction onto the sample substrate; however, they do not contain oily organic constituents characteristic of particles from the Forest/Pine fuels. Particles sampled from Alaskan duff burns showed fractal soot particles both internally and externally mixed with round and irregular shaped particles dominated by carbon and oxygen. The internally mixed particles may have been a result of coagulation. Only trace amounts of inorganic species were measured by X-ray microanalysis of particles from both fuels. Samples from the lignin burn showed amorphous particles dominated by carbon and oxygen. Particle densities and refractive indices for this fuel type were similar to those of the Forest/Pine type, consistent with their high POM content.

The comparisons of the average $f(\mathrm{RH})$ values at $80-85 \%$ $\mathrm{RH}$ for smoke from all burns are shown as scatter plots in Fig. 8a, b for the deliquescence and metastable curves, respectively. The symbols for the average $f(\mathrm{RH})$ values for smoke sampled for a specific burn is denoted by a number (see Table 2) and a color (fuel type). The experimental uncertainties $( \pm 0.08)$ are shown as dotted lines parallel to the solid perfect agreement line. The $f(\mathrm{RH})$ values for smoke particles with weak hygroscopic growth (Forest/Pine and Other fuel types) agreed within experimental uncertainty for the two model estimates. Greater disparity was observed for more hygroscopic particles depending on the model approach. Overall better agreement was accomplished when using the deliquescence curves, at least over the RH range considered here. The exception was for smoke particles from ceanothus (\#9) which agreed well with the metastable curve. Humidification factors for particles generated in burns of two southeastern US/Tropical fuels were overestimated by the models.

Particles with high carbon mass fractions corresponded to low $f(\mathrm{RH})$ values. Figure 9 presents a summary of measured $f(\mathrm{RH})$ values for $\mathrm{RH}=80-85 \%$ as a function of inorganic salt to carbon $(\mathrm{OC}+\mathrm{LAC})$ ratios. The lowest $f(\mathrm{RH})$ values (typically less than 1.1) corresponded to the lowest inorganic salt 


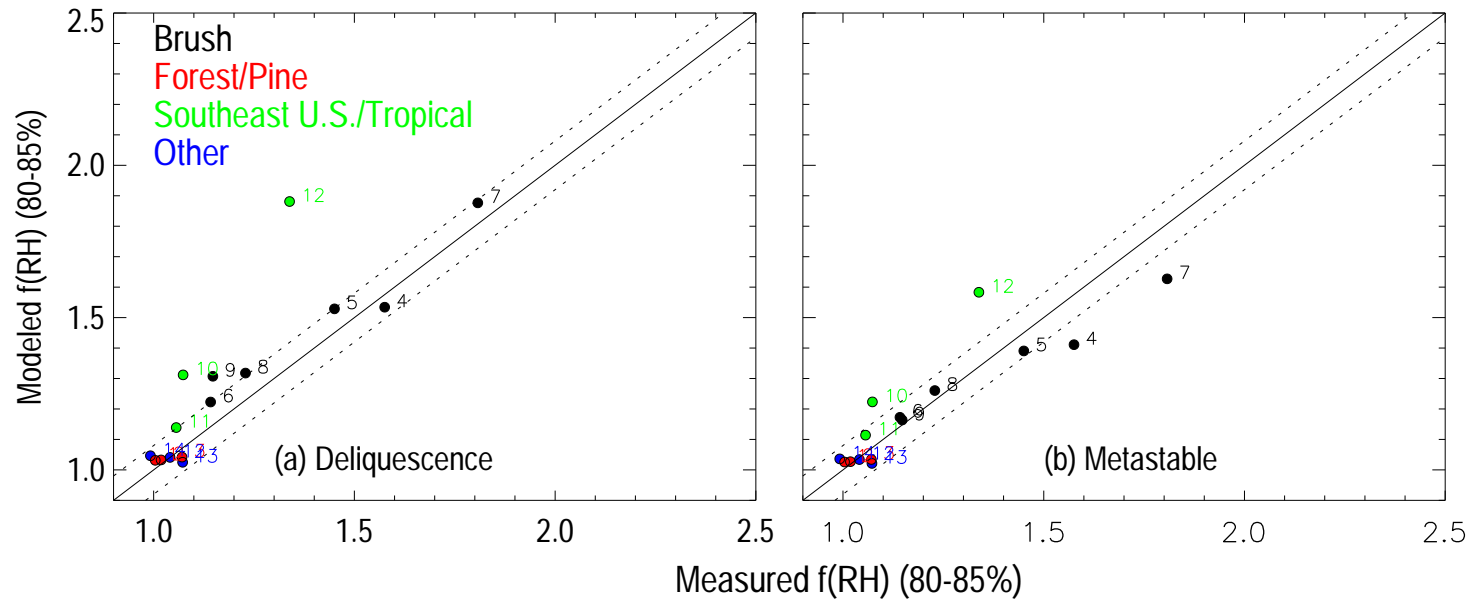

Fig. 8. Comparisons of measured and modeled $f(\mathrm{RH})$ for $\mathrm{RH}=80-85 \%$ for (a) deliquescence, (b) metastable equilibrium derived using the E-AIM model. Fuel species are plotted by number (see Table 2 ) and type (color). Experimental uncertainties $( \pm 0.08)$ are plotted as a dashed line, parallel to the solid perfect agreement line. Humidification factors correspond to $530 \mathrm{~nm}$ wavelength.

to carbon ratios $(<0.05)$ observed for particles from burns of Forest/Pine and Other fuels. The most hygroscopic smoke particles from the Brush fuel type had the highest inorganic salt to carbon ratios. Smoke from the southeast U.S./Tropical type fell within this group as well. From Fig. 9 it is clear that as the carbon content of particles increased relative to the inorganic content, their hygroscopicity decreased. Orthogonal distance regression was applied to the data assuming uncertainties in the inorganic/carbon ratio of \pm 0.02 based on measurement uncertainties in mass concentrations. The regression resulted in a slope of $1.16 \pm 0.09$, an intercept of $0.97 \pm 0.03$, and a correlation coefficient of $r=0.97$ (significant at $99 \%$ confidence level). The intercept suggests an $f(\mathrm{RH})$ value near one for carbon particles containing no inorganic constituents. Carrico et al. (2010) reported a similar relationship for other measurements of hygroscopicity during FLAME 2006 and 2007, and similar results were reported for laboratory experiments by Beaver et al. (2008). This relationship has also been observed for the hygroscopic properties of ambient smoke, as demonstrated by measurements of ambient aged smoke particles measured in Yosemite National Park (Malm et al., 2005; Carrico et al., 2005), as well as biomass smoke measured during flights over the US (Clarke et al., 2007) and ground based measurements in Korea (Kim et al., 2006). The enhancement of hygroscopicity of carbonaceous biomass burning particles mixed internally and externally with inorganic species during the SAFARI2000 study in southern Africa was reported by Semeniuk et al. (2007). Carbonaceous particles (soot and organic particles) processed with sulfate species have also been shown to undergo enhancements in particle hygroscopicity (e.g. Baynard et al., 2006; Garland et al., 2007; Zhang et al., 2008; Khalizov et al., 2009). Our results suggest that, for some fuel types, inorganic species formed through the combustion of

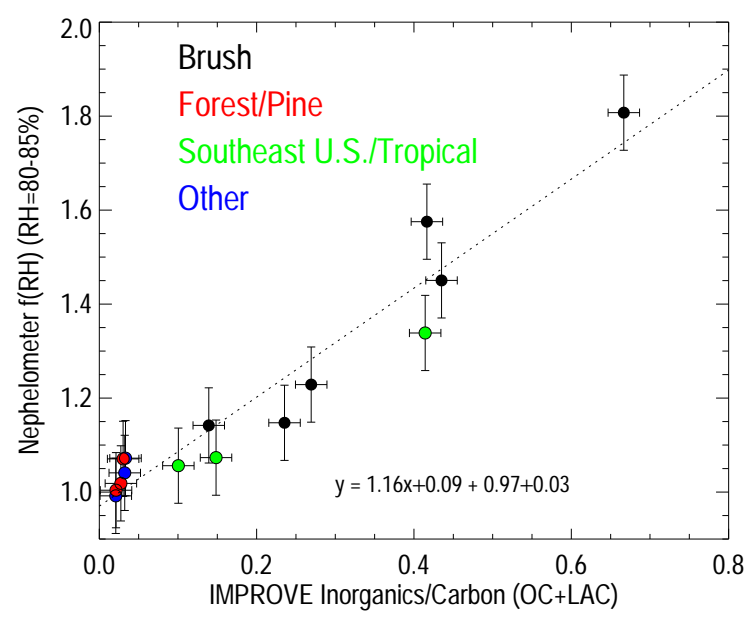

Fig. 9. Measured humidification factor $(f(\mathrm{RH}))(\mathrm{RH}=80-85 \%)$ as a function of inorganic salt to carbon ratio. Carbon includes organic carbon and light absorbing carbon. Fuel type is separated by color. The dotted line refers to a linear regression, with the resulting equation shown. Measurements correspond to a wavelength of $530 \mathrm{~nm}$.

plant matter were present at the time of emission to produce significantly hygroscopic particles without the influence of atmospheric processing. Similar results were reported by Carrico et al. (2010) and Petters et al. (2009) using different measurements of hygroscopicity during FLAME 2006 and 2007.

The range of $f(\mathrm{RH})$ values we report (0.99 to 1.81 ) is consistent with previous observations, both in the laboratory and in the ambient atmosphere. Aircraft measurements of $f(\mathrm{RH})$ during the dry season in Brazil were reported by Kotchenruther and Hobbs (1998) and ranged from 1.01-1.51 
(humid/dry RH of $80 / 30 \%$ ). Higher values occurred under aged conditions, suggesting the importance of atmospheric processing on aerosol hygroscopicity. However, Magi and Hobbs (2003) found similar values of $f(\mathrm{RH})$ for young $(\sim \mathrm{hr}$ old) smoke (1.42) compared to heavily aged smoke (1.44) during aircraft measurements in southern Africa. The importance of fuel composition on hygroscopic properties was suggested by Gras et al. (1999) based on aircraft measurements of smoke $f(\mathrm{RH})$ from north Australian savannah fires (1.37) compared to sulfur-rich peat fires in Indonesia (1.65).

Laboratory chamber measurements of $f(\mathrm{RH})$ during a preliminary FLAME study ranged from 1.10 to 1.51 (hu$\mathrm{mid} / \mathrm{dry} \mathrm{RH}$ of $92 / 10 \%$ ) (Day et al., 2006). Values of $f(\mathrm{RH})$ for smoke from Alaskan duff were comparable between the earlier study and this one ( 1.10 at $\mathrm{RH}=92 \%$ compared to 1.07 at $\mathrm{RH}=80-85$, respectively). However, lower estimates of $f(\mathrm{RH})$ corresponding to smoke from burns of sage were reported during the earlier study compared to this one (1.30 at $\mathrm{RH}=92 \%$ compared to 1.81 at $\mathrm{RH}=80-85 \%$, respectively). Petters et al. (2009) also observed a wide range of hygroscopicity of sage from multiple burns, even within the same experiment. Apparently the source location of sage brush can have a significant effect on the hygroscopic response (Carrico et al., 2010). Measurements of $f(\mathrm{RH})$ by Lewis et al. (2009) during the 2006 FLAME experiment were comparable to our estimates for two available fuels (chamise and ponderosa pine). Values of $f(\mathrm{RH})$ for chamise varied between $1.45-1.8$ as reported by Lewis et al. (2009) and 1.58 reported here. Results for ponderosa pine were $f(\mathrm{RH})=1$ for both studies.

\subsection{Sensitivity of modeled $f(\mathrm{RH})$}

As mentioned in the previous section, there were several assumptions and uncertainties associated with the data and models used to predict $f(\mathrm{RH})$ values. Two of the major assumptions included the value of the molecular weight per carbon weight multiplier used to calculate POM, and the shape factor applied to the DMPS size distributions. These assumptions were important because chemical composition influenced the predicted aerosol water content, and the size distributions affected the derived optical properties. To test the impact on $f(\mathrm{RH})$ values from these assumptions, we performed sensitivity analyses to explore the role of uncertainties in size distributions and chemical composition.

The major source of discrepancy associated with the particle size distributions was the difference in integrated mass from the DMPS and IMPROVE gravimetric fine mass measurements because of the non-sphericity of the aerosols (see Sect. 2.3). The derived shape factors forced the agreement between mass concentrations but also significantly shifted the size distributions, in most cases to smaller size. We computed $f(\mathrm{RH})$ with and without the shape factors applied to the size distributions. The differences in $f(\mathrm{RH})$ were less than \pm 0.02 (at $\mathrm{RH}=80-85 \%$ ) for all fuels and the two model approaches, and were not systematically biased either high or low, suggesting $f(\mathrm{RH})$ was fairly insensitive to change in size distributions. The estimates were well within the \pm 0.08 experimental uncertainty. Averaging size distributions over an entire burn may also have contributed some uncertainty, but changes in particle size distributions during the sampling period were much smaller than any observed from applying shape factors (up to $80 \%$ shift in diameter, see Table 2). The effects from variables that affect light scattering coefficients, such as shifting the size distribution or different optical and physical properties for individual species, canceled when taking the ratio of wet $b_{\mathrm{sp}}$ to dry $b_{\mathrm{sp}}$ in the calculation of $f(\mathrm{RH})$.

Assumptions made in computing aerosol composition could also lead to uncertainties in modeled $f(\mathrm{RH})$. The $\mathrm{OC}$ multiplier used to calculate POM was derived by a mass balance approach, forcing mass closure between reconstructed and gravimetric fine mass. Sensitivity to the choice of the multiplier was investigated by assuming two extreme values (1.2 and 2.5) that for most burns resulted in poor comparisons between gravimetric and reconstructed mass. Using these two multipliers, the model $f(\mathrm{RH})$ was recalculated and compared to the $f(\mathrm{RH})$ computed with the POM derived from mass closure. Changes in $f(\mathrm{RH})$ at $\mathrm{RH}=80-85 \%$ depended on the direction of change in POM concentration. A decrease in POM concentration resulted in higher $f(\mathrm{RH})$ values due to the increase in inorganic mass fractions, and vice versa. For both the deliquescence and metastable equilibrium cases, the effect of the multiplier was within experimental uncertainty $( \pm 0.08)$ at $80-85 \% \mathrm{RH}$ for most fuels. The fuels with the largest sensitivity $(> \pm 0.08)$ corresponded to those with high inorganic content. Particles from burns of sage/rabbit brush, Puerto Rico fern, and ceanothus were the most sensitive to the multiplier, especially for the case when the multiplier was 2.5 . This sensitivity study suggested that for particles with high inorganic mass fractions, the $f(\mathrm{RH})$ values can be sensitive to the magnitude of the POM mass fraction because of its role in depressing the hygroscopic growth at high RH, specifically because POM was considered non-hygroscopic.

The sensitivity to the assumed speciation of inorganic mass was tested by calculating the dry aerosol physical and optical properties such as refractive index, density and shape factor by assuming a different mixture of inorganic salts $(\mathrm{KCl}, \mathrm{NaCl}$, ammoniated sulfate by degree of acidity and $\mathrm{NH}_{4} \mathrm{NO}_{3}$ ). Differences in the dry aerosol properties were negligible. Testing the sensitivity of derived aerosol water content to the presence of potassium salts was more difficult. As mentioned previously, the E-AIM model does not consider potassium salts in its formulation; therefore we assumed all of the potassium was sodium to derive aerosol water content. This assumption probably did not have a significant effect on results because the deliquescence $\mathrm{RH}$ of most of the potassium salts are higher than the upper limit of the RH scans performed during the measurements and so may not have had a measureable impact $\left(\mathrm{KCl}: 84 \% ; \mathrm{K}_{2} \mathrm{SO}_{4}\right.$ : 
97\%; $\mathrm{KNO}_{3}: 92.3 \%$, Freney et al. (2009) and references therein). However, it is possible that the modeled $f(\mathrm{RH})$ values were slightly higher than they would be if potassium salts were used to derive water contents. To illustrate, hygroscopic parameters $(\kappa)$ for potassium and sodium salts (Carrico et al., 2010, and references therein) were converted to GF (at $\mathrm{RH}=90 \%$ ) and suggested that $\mathrm{NaCl}$ is only slightly more hygroscopic at $90 \% \mathrm{RH}(\mathrm{GF}=2.23)$ than $\mathrm{KCl}(\mathrm{GF}=2.15), \mathrm{KNO}_{3}$ $(\mathrm{GF}=2.11)$ or $\mathrm{K}_{2} \mathrm{SO}_{4}(\mathrm{GF}=1.78)$. Although the magnitude of $f(\mathrm{RH})$ may not be significantly different at high $\mathrm{RH}$ when assuming sodium instead of potassium salts to derive water content, the features in the $f(\mathrm{RH})$ curves might be. Specifically, the deliquescence point for measured and modeled $f(\mathrm{RH})$ values could occur at different $\mathrm{RH}$ values, as suggested by the $f(\mathrm{RH})$ curves presented in Fig. 6 .

The normalization of the modeled $f(\mathrm{RH})$ curves also contributed some uncertainty. The modeled curves were adjusted so that $f(\mathrm{RH})$ equaled one at the same dry $\mathrm{RH}$ value as the measurements, essentially accounting for any water that might have been associated with the measured particles at low RH. The consequences of this adjustment were noticeable at high RH in the suppression of the metastable equilibrium curve compared to the deliquescence curve, especially for the cases with significant hygroscopic growth. The suppression of the metastable equilibrium $f(\mathrm{RH})$ curve implied that the particles were dry at low (20-25\%) RH and were humidified on the deliquescence curve rather than existing in metastable equilibrium.

Other assumptions in modeled $f(\mathrm{RH})$ include simplified treatment for calculating aerosol water content. We made simple assumptions regarding the average aerosol composition over a burn period when in reality the composition of the particles was most likely complex and evolving over the burn duration. We simplified the hygroscopic growth by assuming only inorganic salts take up water and POM was completely non-hygroscopic. The models assumed homogeneous, internally-mixed particles across the accumulation mode size range, when in fact SEM images suggested heterogeneous particles that may be internally or externally mixed. Others also have observed this heterogeneity in ambient smoke particles (Li et al., 2003; Pósfai et al., 2003; Hand et al., 2005; Semeniuk et al., 2007). Additionally, GF data suggested there may be considerable heterogeneity in the particle response to water uptake, both for a given size and across the range of accumulation mode sizes (Petters et al., 2009; Carrico et al., 2010). Particle heterogeneity could lead to differences in hygroscopic growth across the accumulation mode size range, resulting in particle populations growing into optically efficient sizes at varying RHs and possibly contributing to the smoothed, continuous growth observed in the measurements. Given all of these simple assumptions we found acceptable agreement (within experimental uncertainty) between the modeled and measured $f(\mathrm{RH})$ at high $\mathrm{RH}$ for smoke from most of the fuels examined here.

\section{Summary}

Measured humidification factors $(f(\mathrm{RH}))$ from nephelometry demonstrated a range in hygroscopicity for young smoke particles from fourteen biomass fuels burned in combustion facility experiments. Estimates ranged from $0.99 \pm 0.08$ to $1.81 \pm 0.08$ at $80-85 \% \mathrm{RH}$ depending on fuel type. Forest/Pine fuels produced particles with the least hygroscopic properties and Brush fuels produced smoke with the most hygroscopic properties. These ranges in hygroscopicity with fuel type are comparable to the rankings reported by Petters et al. (2009) for similar fuels. Chemical and physical characteristics of smoke particles were computed for each fuel from concurrent chemical composition measurements. The average dry refractive index $(n=m-k i, 1.63 \pm 0.07-$ $0.14 \pm 0.11 i)$, densities $\left(1.6 \pm 0.2 \mathrm{~g} \mathrm{~cm}^{-3}\right)$, molecular carbon to organic carbon multiplier $(1.7 \pm 0.3)$ and dynamic shape factors $(1.3 \pm 0.3)$ were found in good agreement with previous estimates for biomass smoke.

Using measured size distributions and chemical composition, we modeled $f(\mathrm{RH})$ values as a function of $\mathrm{RH}$ using a thermodynamic equilibrium model and the ZSR assumption to estimate the mixed aerosol water content; Mie theory was used to compute aerosol optical properties assuming internally mixed spherical particles. Agreement between measured and modeled $f(\mathrm{RH})$ values were within experimental uncertainties for particles from most of the fuels, suggesting that the simple assumptions applied in the model were adequate to account for measured water uptake. Specifically, carbon, the dominant fine mass species for smoke emitted from most fuels, was treated as non-hygroscopic. Although it is possible that carbon did absorb some water, the contribution to $f(\mathrm{RH})$ from organics would have to be less than \pm 0.08 (experimental uncertainty) because for most cases the measured and modeled $f(\mathrm{RH})$ agreed within this range; therefore we conclude that the organic species were not significantly hygroscopic.

Values of $f(\mathrm{RH})$ at $\mathrm{RH}=80-85 \%$ were linearly correlated with inorganic salt to carbon ratios. These results confirmed previous findings of hygroscopic growth of young biomass smoke (e.g. Day et al., 2006; Petters et al., 2009; Carrico et al., 2010). The smoke characteristics presented here demonstrated that fuels with higher inorganic mass fractions and soot internally and externally mixed with inorganic species resulted in higher $f(\mathrm{RH})$ values, in some cases nearing the hygroscopic properties of pure inorganic salts. In contrast, the predominantly carbon particles resulted in only minimal growth at high RH (80-85\%). Although these particles did not grow significantly at high $\mathrm{RH}$, their interaction with water in the atmosphere is not ruled out, as Petters et al. (2009) observed cloud nucleating ability from smoke particles from several similar fuels. The agreement between measured and modeled $f(\mathrm{RH})$ values provided evidence of hygroscopic young smoke most likely due to inorganic species burned in the plant material, as carbonaceous species were assumed 
non-hygroscopic in the model. These results are important for understanding the range of $f(\mathrm{RH})$ values reported for ambient smoke and for improving our ability to parameterize the behavior of biomass smoke aerosols in climate studies and visibility regulatory efforts.

Acknowledgements. We gratefully acknowledge the USFS Fire Science Laboratory staff for their valuable support and assistance during the study, including Cyle Wold and Wei Min Hao. We also thank those who collected and provided fuels for the study. Funding was provided by the Joint Fire Science Program and the US National Park Service.

The PNNL research group acknowledges support provided from the Atmospheric Science Program of the Office of Biological and Environmental Research (OBER), US Department of Energy. Electron microscopy analyses were performed in the Environmental Molecular Sciences Laboratory (EMSL), a national scientific user facility sponsored by the Department of Energy's Office of Biological and Environmental Research at Pacific Northwest National Laboratory (PNNL). PNNL is operated by the US Department of Energy by Battelle Memorial Institute under contract DE-AC06-76RL0 1830.

Disclaimer: the assumptions, findings, conclusions, judgments and views presented herein are those of the authors and should not be interpreted as necessarily representing the National Park Service policies.

Edited by: A. Chen

\section{References}

Anderson, T. L., Covert, D. S., Marshall, S. F., Laucks, M. L., Charlson, R. J., Waggoner, A. P., Ogren, J. A., Caldow, R., Holm, R. L., Quant, F. R., Sem, G. J., Wiedensohler, A., Ahlquist, N. A., and Bates, T. S.: Performance characteristics of a high-sensitivity, three-wavelength, total scatter/backscatter nephelometer, J. Atmos. Ocean. Tech., 13, 967-986, 1996.

Baron, P. A. and Willeke, K.: Gas and Particle Motion. In Aerosol Measurement Principles, Techniques and Applications, edited by K. Willeke and P. Baron, Van Nostrand Reinhold, New York, 2340, 1993.

Baynard, T., Garland, R. M., Ravishankara, A. R., Tolbert, M. A., and Lovejoy, E. R.: Key factors influencing the relative humidity dependance of aerosol light scattering, Geophys. Res. Lett., 33, L06813, doi:10.1029/2005JL024898, 2006.

Beaver, M. R., Garland, R. M., Hasenkopf, C. A., Baynard, T., Ravishankara, A. R., and Tolbert, M. A.: A laboratory investigation of the relative humidity dependence of light extinction by organic compounds from lignin combustioin, Environ. Res. Lett., 3, 045003, doi:10.1088/1748-9326/3/4/045003, 2008.

Carrico, C. M., Kreidenweis, S. M., Malm, W. C., Day, D. E., Lee, T., Carrillo, J., McMeeking, G. R., and Collett, Jr., J. L.: Hygroscopic growth behavior of a carbon-dominated aerosol in Yosemite National Park, Atmos. Environ., 39, 1393-1404, 2005.

Carrico, C. M., Petters, M. D., Kreidenweis, S. M., Collett Jr., J. L., Engling, G., and Malm, W. C.: Aerosol hygroscopicity and cloud droplet activation of extracts of filters from biomass burning experiments, J. Geophys. Res., 113, D08206, doi:10.1029/2007JD009274, 2008.
Carrico, C. M., Petters, M. D., Kreidenweis, S. M., Sullivan, A. P., McMeeking, G. R., Levin, E. J. T., Engling, G., Malm, W. C., and Collett Jr., J. L.: Water uptake and chemical composition of fresh aerosols generated in open burning of biomass, Atmos. Chem. Phys., 10, 5165-5178, doi:10.5194/acp-10-5165-2010, 2010.

Chakrabarty, R. K., Moosmuller, H., Garro, M. A., Arnott, W. P., Walker, J., Susott, R. A., Babbitt, R. E., Wold, C. E., Lincoln, E. N., and Hao, W. M.: Emissions from the laboratory combustion of wildland fuels: Particle morphology and size, J. Geophys. Res., 111, D07204, doi:10.1029/2005JD006659, 2006.

Chen, L.-W. A., Moosmüller, H., Arnott, W. P., Chow, J. C., Watson, J. G., Susott, R. A., Babbitt, R. E., Wold, C. E., Lincoln, E. N., and Hao, W. M.: Particles emissions from laboratory combustion of wildland fuels: In-situ optical and mass measurements, Geophys. Res. Lett., 33, L04803, doi:10.1029/2005GL024838, 2006.

Chen, L.-W. A., Moosmüller, H., Arnott, W. P., Chow, J. C., and Watson, J. G.: Emissions from laboratory combustion of wildland fuels: Emission factors and source profiles, Environ. Sci. Technol., 41(12), 4317-4325, 2007.

Chow, J. C., Watson, J. G., Chen, L.-W. A., Chang, M. C. O., Robinson, N. F., Trimble, D., and Kohl, S.: The IMPROVE_A temperature protocol for thermal/optical carbon analysis: Maintaining consistency with a long-term database, J. Air Waste Manage. Assoc., 57, 1014-1023, 2007.

Clarke, A., McNaughton, C., Kapustin, V., Shinozuka, Y., Howell, S., Dibb, J., Xhou, J., Anderson, B., Brekhovskikh, V., Turner, H., and Pinkerton, M.: Biomass burning and pollution aerosol over North America: Organic components and their influence on spectral optical properties and humidification response, J. Geophys. Res. 112, D12S18, doi:10.1029/2006JD007777, 2007.

Clegg, S. L., Brimblecombe, P., and Wexler, A. S.: A thermodynamic model of the system $\mathrm{H}^{+}-\mathrm{NH}_{4}{ }^{+}-\mathrm{Na}^{+}-\mathrm{SO}_{4}{ }^{2-}-\mathrm{NO}^{-}$$\mathrm{Cl}^{-}-\mathrm{H} 2 \mathrm{O}$ at 298.15 K. J. Phys. Chem. A, 102, 2155-2171, 1998.

Day, D. E., Malm, W. C., Kreidenweis, S. M.: Aerosol light scattering measurements as a function of relative humidity, J. Air Waste Manage. Assoc., 50, 710-716, 2000.

Day, D. E., Hand, J. L., Carrico, C. M., Engling, G., and Malm, W. C.: Humidification factors from laboratory studies of fresh smoke from biomass fuels, J. Geophys. Res., 111, D22202, doi:10.1029/2006JD007221, 2006.

DeMott, P. J., Petters, M. D., Prenni, A. J., Carrico, C. M., Kreidenweis, S. M., Collett Jr., J. L., and Moosmüller, H.: Ice nucleation behavior of biomass combustion particles at cirrus temperatures, J. Geophys. Res., 114, D16205, doi:10.1029/2009JD012036, 2009.

Dick, W. D., Saxena, P., and McMurry, P. H.: Estimation of water uptake by organic compounds in submicron aerosols measured during the Southeastern Aerosol and Visibility Study, J. Geophys. Res., 105, 1471-1479, 2000.

El-Zanan, H. S., Lowenthal, D. H., Zielinska, B., Chow, J. C., and Kumar, N.: Determination of the organic aerosol mass to organic carbon ratio in IMPROVE samples, Chemosphere, 60, 485-496, 2005.

Engling, G., Carrico, C. M., Kreidenweis, S. M., Collett, Jr., J. L., Day, D. E., Malm, W. C., Hao, W. M., Lincoln, E., Iinuma, Y., and Herrmann, H.: Determination of levoglucosan in biomass combustion aerosol by high performance anion exchange chromatography with pulsed amperometric detection, Atmos. Envi- 
ron.,40, S299-S311, 2006.

Freney, E. J., Martin, S. T., and Buseck, P. R.: Deliquescence and efflorescence of potassium salts relevant to biomass-burning aerosol particles, Aerosol Sci. Technol., 43(8), 799-807, 2009.

Garland, R. M., Ravishankara, A. R., Lovejoy, E. R., Tolbert, M. A., and Baynard, T.: Parameterization for the relative humidity dependence of light extinction: Organicammonium sulfate aerosol, J. Geophys. Res., 112, D19303, doi:10.1029/2006JD008179, 2007.

Gras, J. L., Jensen, J. B., Okada, K., Ikegami, M., Zizen, Y., and Makino, Y.: Some optical properties of smoke aerosol in Indonesia and tropical Australia, Geophys. Res. Lett., 26(10), 13931396, 1999.

Gwaze, P., Schmid, O., Annegarn, H. J., Andreae, M. O., Huth, J. and Helas, G.: Comparison of three methods of fractal analysis applied to soot aggregates from wood combustion, J. Aerosol Sci., 37, 820-838, 2006.

Hand, J. L., Kreidenweis, S. M., Slusser J., and Scott, G.: Comparisons of aerosol optical properties derived from Sun photometry to estimates inferred from surface measurements in Big Bend National Park, Texas, Atmos. Environ., 38, 6813-6821, 2004.

Hand, J. L., Malm, W. C., Laskin, A., Day, D., Lee, T., Wang, C., Carrico, C., Carrillo, J., Cowin, J. P., Collett, Jr., J., and Iedema, M. J.: Optical, physical, and chemical properties of tar balls observed during the Yosemite Aerosol Characterization Study, J. Geophys. Res., 110, D21210, doi:10.1029/2004JD005728, 2005.

Hansen, J., Sato, M., Ruedy, R., Nazarenko, L., Lacis, A., Schmidt, G. A., Russell, G., Aleinov, I., Bauer, M., Bauer, S., Bell, N., Cairns, B., Canuto, V., Chandler, M., Cheng, Y., Del Genio, A., Faluvegi, G., Fleming, E., Friend, A., Hall, T., Jackman, C., Kelley, M., Kiang, N., Koch, D., Lean, J., Lerner, J., Lo, K., Menon, S., Miller, R., Minnis, P., Novakov, T., Oinas, V., Perlwitz, Ja., Perlwitz, Ju., Rind, D., Romanou, A., Shindell, D., Stone, P., Sun, S., Tausnev, N., Thresher, D., Wielicki, B., Wong, T., Yao, M., and Zhang, S.: Efficacy of climate forcings, J. Geophys. Res., 110, D18104, doi:10.1029/2005JD005776, 2005.

Hasan, H. and Dzubay, T. G.: Apportioning light extinction coefficients to chemical species in atmospheric aerosol, Atmos. Environ., 17(8), 1573-1581, 1983.

Hinds, W. C.: Aerosol Technology: Properties, Behavior and Measurement of Airborne Particles, 2nd ed. John Wiley \& Sons, New York, 42-73, 1999.

Hoffer, A., Gelencsér, A., Guyon, P., Kiss, G., Schmid, O., Frank, G. P., Artaxo, P., and Andreae, M. O.: Optical properties of humic-like substances (HULIS) in biomass-burning aerosols, Atmos. Chem. Phys., 6, 3563-3570, doi:10.5194/acp-6-3563-2006, 2006.

Hopkins, R. J., Lewis, K., Desyaterik, Y., Wang, Z., Tivanski, A. V., Arnott, W. P., Laskin, A., and Gilles, M. K.: Correlations among Optical, Chemical and Physical Properties of Biomass Burn Aerosols, Geophys. Res. Lett., 34, L18806, doi:10.1029/2007GL0305022007, 2007.

Hungershoefer, K., Zeromskiene, K., Iinuma, Y., Helas, G., Trentmann, J., Trautmann, T., Parmar, R. S., Wiedensohler, A., Andreae, M. O., and Schmid, O.: Modelling the optical properties of fresh biomass burning aerosol produced in a smoke chamber: results from the EFEU campaign, Atmos. Chem. Phys., 8, 34273439, doi:10.5194/acp-8-3427-2008, 2008.

Khalizov, A. F., Zhang, R., Zhang, D., Xue, H., Pagels, J., and
McMurry, P. H.: Formation of highly hygroscopic soot aerosols upon internal mixing with sulfuric acid vapor, J. Geophys. Res., 114, D05208, doi:10.1029/2008JD010595, 2009.

Kim, J., Yoon, S.-C., Jefferson, A., and Kim, S.-W.: Aerosol hygroscopic properties during Asian dust, pollution and biomass burning episodes at Gosan, Korea in April 2001, Atmos. Environ. 40, 1550-1560, 2006.

Kirchstetter, T. W., Novakov, T., and Hobbs, P. V.: Evidence that the spectral dependence of light absorption by aerosols is affected by organic carbon, J. Geophys. Res., 109, D21208, doi:10.1029/2004JD004999, 2004.

Kotchenruther, R. A., and Hobbs, P. V.: Humidification factors of aerosol from biomass burning in Brazil, J. Geophys. Res., 103(D24), 32081-32089, 1998.

Krämer, L., Pöschl, U., and Niessner, R., Microstructural rearrangement of sodium chloride condensation aerosol particles on interaction with water vapor, J. Aerosol Sci., 31(6), 673-685, 2000.

Laskin, A., Cowin, J. P., Iedema, M. J.: Analysis of individual environmental particles using modern methods of electron microscopy and X-ray microanalysis, J. Electron Spectrosc. Related Phenomena, 150, 260-274, doi:10.1016/j.elspec.2005.06.008, 2006.

Laskin, A., Smith, J. S., and Laskin, J.: Molecular Characterization of Nitrogen Containing Organic Compounds in Biomass Burning Aerosols Using High Resolution Mass Spectrometry, Environ. Sci. Technol., 43, 3764-3771, doi:10.1021/es803456n, 2009.

Levin, E. J. T., McMeeking, G. R., Carrico, C., Mack, L., Kreidenweis, S. M., Wold, C. E., Moosmüller, H., Arnott, W. P., Hao, W. M., Collett Jr., J. L., and Malm, W. C.: Biomass burning smoke aerosol properties measured during FLAME 2, J. Geophys. Res., doi:10.1029/2009JD013601, in press, 2010.

Lewis, K. A., Arnott, W. P., Moosmüller, H., Chakrabarty, R. K., Carrico, C. M., Kreidenweis, S. M., Day, D. E., Malm, W. C., Laskin, A., Jimenez, J. L., Ulbrich, I. M., Huffman, J. A., Onasch, T. B., Trimborn, A., Liu, L., and Mishchenko, M. I.: Reduction in biomass burning aerosol light absorption upon humidification: roles of inorganically-induced hygroscopicity, particle collapse, and photoacoustic heat and mass transfer, Atmos. Chem. Phys., 9, 8949-8966, doi:10.5194/acp-9-8949-2009, 2009.

Li, J., Pósfai, M., Hobbs, P. V., and Buseck, P. R.: Individual aerosol particles from biomass burning in southern Africa: 2. Compositions and aging of inorganic particles, J. Geophys. Res., 108(D13), 8484, doi:10.1029/2002JD002310, 2003.

Lide, D. R.: CRC Handbook of chemistry and physics, CRC Taylor and Francis, 2008.

Magi, B. I. and Hobbs, P. V.: Effects of humidity on aerosols in southern Africa during the biomass burning season, J. Geophys. Res., 108(D13), 8495, doi:10.1029/2002JD002144, 2003.

Malm. W. C. and Kreidenweis, S. M.: The effects of models of aerosol hygroscopicity on the apportionment of extinction, Atmos. Environ., 31(13), 1965-1976, 1997.

Malm, W. C., Day, D. E., Kreidenweis, S. M., Collett, J. L., and Lee, T.: Humidity-dependent optical properties of fine particles during the Big Bend Regional Aerosol and Visibility Observational Study, J. Geophys. Res., 108(D9), 4279, doi:10.1029/2002JD002998, 2003.

Malm, W. C., Schichtel, B. A., Pitchford, M. L., Ashbaugh, L. L., and Eldred, R. E.: Spatial and monthly trends in speciated fine 
particle concentration in the United States, J. Geophys. Res., 109, D03306, doi:10.1029/2003JD003739, 2004.

Malm, W. C., Day, D. E., Kreidenweis, S. M., Collett, Jr., J. L., Carrico, C., McMeeking, G., and Lee, T.: Hygroscopic properties of an organic-laden aerosol, Atmos. Environ., 39, 4969-4982, 2005.

Malm, W. C. and Hand, J. L.: An examination of the physical and optical properties of aerosols collected in the IM PROVE program, Atmos. Environ., 41, 3407-3427, 2007.

McMeeking, G. R., Kreidenweis, S. M., Carrico, C. M., Lee, T., and Collett Jr., J. L.: Observations of smoke-influenced aerosol during the Yosemite Aerosol Characterization Study: Size distributions and chemical composition, J. Geophys. Res., 110, D09206, doi:10.1029/2004JD005389, 2005.

McMeeking, G. R., Kreidenweis, S. M., Baker, S., Carrico, C. M., Chow, J. C., Collett, Jr., J. L., Hao, W. M., Holden, A. S., Kirchstetter, T. W., Malm, W. C., Moosmüller, H., Sullivan, A. P., and Wold, C. E.: Emissions of trace gases and aerosols during the open combustion of biomass in the laboratory, J. Geophys. Res., 114, D19210, doi:10.1029/2009JD011836, 2009.

Naeher, L. P., Brauer, M., Lipsett, M., Zelikoff, J. T., Simpson, C. D., Koenig, J. Q., and Smith, K. R.: Woodsmoke health effects: A review, Inhalation Toxic. 19, 67-106, 2007.

Ouimette, J. R. and Flagan, R. C.: The extinction coefficient of multi-component aerosols., Atmos. Environ., 16(10), 24052419, 1982.

Park, R. J., Jacob, D. J., Chin, M., and Martin, R. V.: Sources of carbonaceous aerosols over the United States and implications for natural visibility, J. Geophys. Res., 108(D12), 4355, doi:10.1029/2002JD003190, 2003.

Park, R. J., Jacob, D. J., and Logan, J. A.: Fire and biofuel contributions to annual mean aerosol mass concentrations in the United States, Atmos. Environ., 41, 7389-7400, 2007.

Petters, M. D., Carrico, C. M., Kreidenweis, S. M., Prenni, A. J., DeMott, P. J., Collett Jr., J. L., and Moosmüller, H.: Cloud condensation nucleation activity of biomass burning aerosol, J. Geophys. Res., 114, D22205, doi:10.1029/2009JD012353, 2009.

Pósfai, M., Simonics, R., Li, J., Hobbs, P. V., and Buseck, P. R.: Individual aerosol particles from biomass burning in southern Africa: 1. Compositions and size distributions of carbonaceous particles, J. Geophys. Res., 108(D13), 8483, doi:10.1029/2002JD002291, 2003.

Rader, D. J. and McMurry, P. H.: Application of the tandem differential mobility analyzer to studies of droplet growth or evaporation, J. Aerosol Sci., 17, 771-787, 1986.

Reid, J. S., Koppmann, R., Eck, T. F., and Eleuterio, D. P.: A review of biomass burning emissions part II: intensive physical properties of biomass burning particles, Atmos. Chem. Phys., 5, 799825, doi:10.5194/acp-5-799-2005, 2005a.
Reid, J. S., Eck, T. F., Christopher, S. A., Koppmann, R., Dubovik, O., Eleuterio, D. P., Holben, B. N., Reid, E. A., and Zhang, J.: A review of biomass burning emissions part III: intensive optical properties of biomass burning particles, Atmos. Chem. Phys., 5, 827-849, doi:10.5194/acp-5-827-2005, 2005 b.

Russell, L. M.: Aerosol organic-mass-to-organic carbon ratio measurements, Environ. Sci. Technol., 37, 2982-2987, 2003.

Schneider, J., Weimer, S., Drewnick, F., Borrmann, S., Helas, G., Gwaze, P., Schmid, O., Andreae, M. O., and Kirchner, U.: Mass spectrometric analysis and aerodynamic properties of various type of combustion-related aerosol particles, Internat. J. Mass. Spect., 258, 37-49, doi:10.1016/j.ijms.2006.07.008, 2006.

Seinfeld, J. H. and Pandis, S. N.:Atmospheric Chemistry and Physics, John Wiley, Hoboken, NJ, 1998.

Semeniuk, T. A., Wise, M. E., Martin, S. T., Russell, L. M., and Buseck, P. R.: Hygroscopic behavior of aerosol particles from biomass fires using environmental transmission electron microscopy, J. Atmos. Chem., 56, 259-273, 2007.

Smith, J., Laskin, A., and Laskin, J.: Molecular Characterization of Biomass Burning Aerosols Using High Resolution Mass Spectrometry, Anal. Chem., 81, 1512-1521, doi: 10.1021/ac8020664, 2009.

Spracklen, D. V., Logan, J. A., Mickley, L. J., Park, R. J., Yevich, R., Westerling, A. L., and Jaffe, D. A.: Wildfires drive interannual variability of organic carbon in the western U.S. in summer, Geophys. Res. Lett., 34, L16816, doi:10.1029/2007GL030037, 2007.

Stokes, R. H. and Robinson, R. A.: Interactions in aqueous nonelectrolyte solutions, I, Solute-solvent equilibria, J. Phys. Chem., 70, 2126-2131, 1966.

Sullivan, A. P., Holden, A. S., Patterson, L. A., McMeeking, G. R., Kreidenweis, S. M., Malm, W. C., Hao, W. M., Wold, C. E., and Collett Jr., J. L.: A method for smoke marker measurements and its potential application for determining the contribution of biomass burning from wildfires and prescribed fires to ambient PM2.5 organic carbon, J. Geophys. Res., 113, D22303, doi:10.1029/2008JD010216, 2008.

Turpin, B. J. and Lim, H.-J.: Species contributions to PM2.5 mass concentrations: Revisiting common assumptions for estimating organic mass, Aerosol. Sci. Technol., 35, 602-610, 2001.

Vestin, A., Rissler, J., Swietlicki, E., Frank, G. P., and Andreae, M. O.: Cloud-nucleating properties of the Amazonian biomass burning aerosol: Cloud condensation nuclei measurements and modeling, J. Geophys. Res., 112, D14201, doi:10.1029/2006JD008104, 2007.

Zhang, R., Khalizov, A. F., Pagels, J., Zhang, D., Xue, H., and McMurry, P. H.: Variability in morphology, hygroscopicity, and optical properties of soot aerosols during atmospheric processing, P. Natl. Acad. Sci., 105(30), 10291-10296, 2008. 